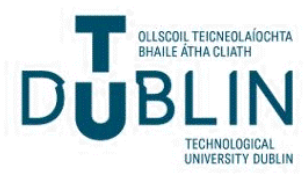

Technological University Dublin ARROW@TU Dublin

2007-01-01

\section{Play and Technology for Children aged 4-12}

\author{
Stella Downey \\ Technological University Dublin, Stella.Downey@tudublin.ie \\ Noirin Hayes \\ Technological University Dublin, noirin.hayes@tudublin.ie \\ Brian O'Neill \\ Technological University Dublin, brian.oneill@tudublin.ie
}

Follow this and additional works at: https://arrow.tudublin.ie/cserrep

Part of the Family, Life Course, and Society Commons

\section{Recommended Citation}

Downey, S., Hayes, N., O'Neill, B.: Play and technology for children aged 4-12. Study commissioned by the Office of the Minister for Children, Government of Ireland. 2007.

This Report is brought to you for free and open access by the Centre for Social and Educational Research at ARROW@TU Dublin. It has been accepted for inclusion in Reports by an authorized administrator of ARROW@TU

Dublin. For more information, please contact

arrow.admin@tudublin.ie, aisling.coyne@tudublin.ie, gerard.connolly@tudublin.ie.

Funder: Department of Health and Children, Ireland

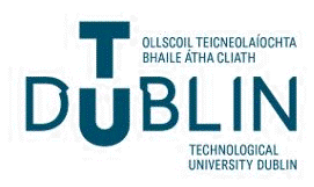




\title{
Play and Technology for children aged 4-12
}

\author{
Stella Downey \\ Noirin Hayes \\ Brian O’Neill
}

Centre for Social and Educational Research

Dublin Institute of Technology

Office of the Minister for Children 


\section{Contents}

Executive Summary ..................................................................................................... 1

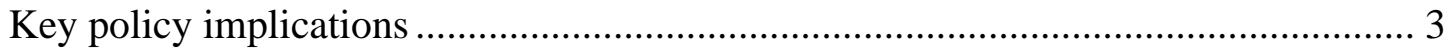

1 Introduction ................................................................................................................... 4

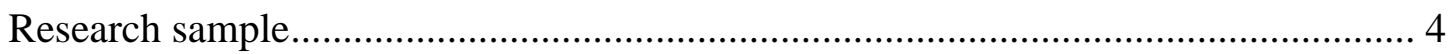

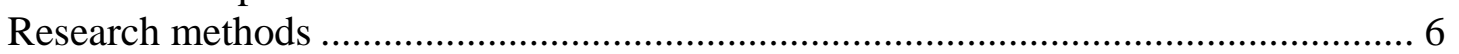

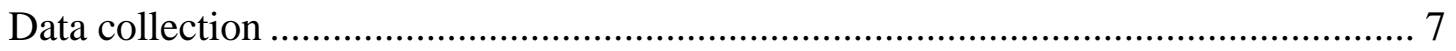

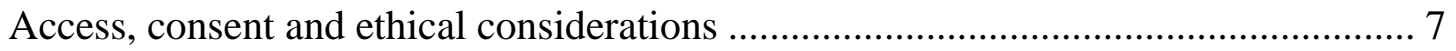

2 Review of literature on children, play and technology ............................................. 8

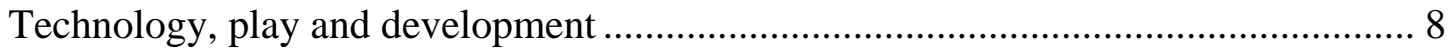

Technology's impact on development ...................................................................... 9

Negative impact of technology ............................................................................. 11

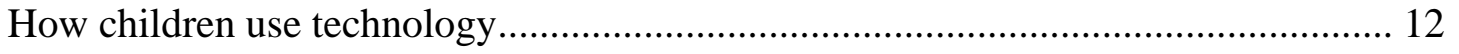

3 Play and technology for children, aged 4-12............................................................ 14

What children like about playing............................................................................... 15

Information and entertainment media in the home ………….................................... 16

Screen-based entertainment media ………………………...................................... 19

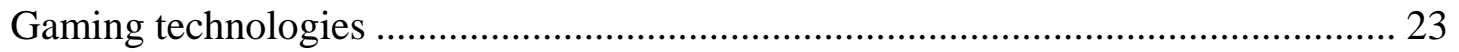

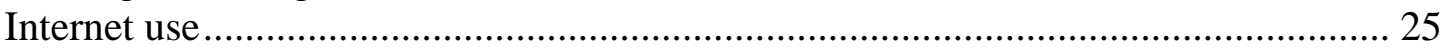

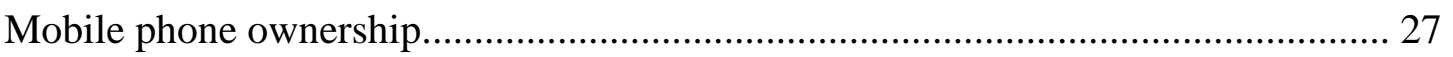

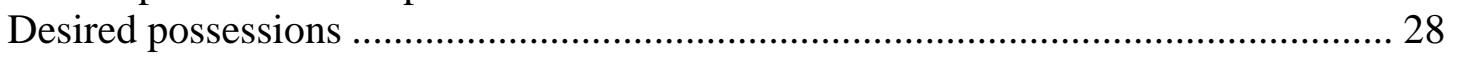

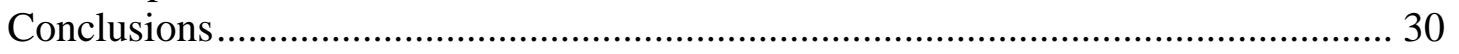

$4 \quad$ What children and adults say about play and technology ....................................... 31

General findings........................................................................................................ 31

What parents and teachers say about play .................................................................... 42

Parents' views on children's use of technology ............................................................. 42

Teachers' views on children's use of technology .......................................................... 44

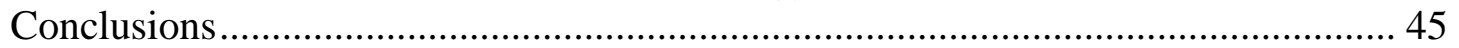

5 Conclusions and Recommendations .......................................................................... 47

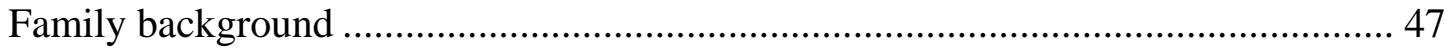

Playing with friends .............................................................................................. 47

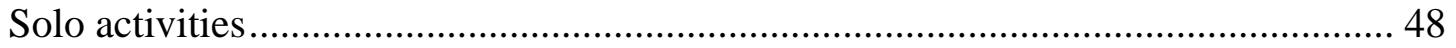

Domestic access to technology ……………………….......................................... 49

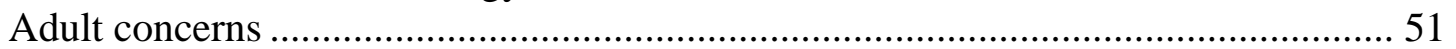

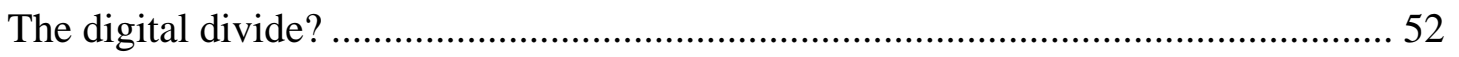

Limitations on comparisons .................................................................................. 52

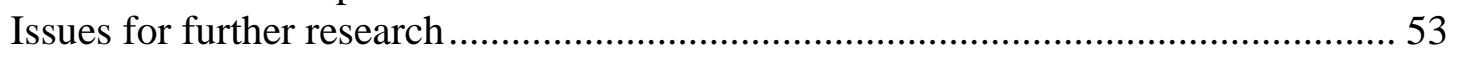

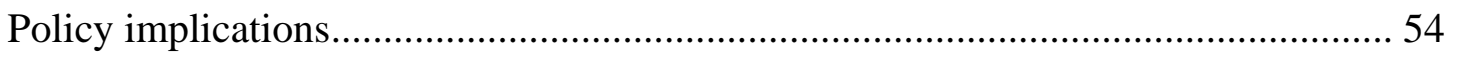

Bibliography ...................................................................................................................... 56

Appendix 1: Play and Technology Questionnaire for younger children (aged 4-8)........ 59

Appendix 2: Play and Technology Questionnaire for older children (aged 8-12)............ 62 


\section{Executive Summary}

In 2004, having identified the intersection of technology and children's play as a key topic, the National Children's Office commissioned this research study from the Centre for Social and Educational Research at the Dublin Institute of Technology. Taking as its definition of play, 'the freely chosen, personally directed, intrinsically motivated behaviour that actively engages the child' (NCO, 2004, p. 10), the study addresses the kinds of technologies that are present in the daily lives of children in Ireland today, together with the principal patterns of usage and consumption of this technology and its place in children's day-to-day play behaviour. The research study sought to give children a voice to express what technology use means to them and also considered how children's perspectives have a role in informing policy in relation to play and technology.

Children, aged between 4 and 12, from 10 primary schools throughout the country participated in the study. A combination of qualitative and quantitative data was gathered from 292 children, as well as adults, parents and teachers.

The findings on how children like to spend time with their friends suggest that, given the opportunity, children will make their own fun. Sports and other outdoor activities are very popular. However, when alone, children often turn to technology for entertainment and most of them have quite a high degree of access to technology. When playing console or computer games, most children like to play against another person. Interest in indoor-based entertainment appears to increase with age, although certain factors, such as weather, time of year and access to facilities, may also influence a child's choices.

Technology is widely present in the average home in Ireland. Ownership of media technology appears to increase with age and major gender bias is not largely apparent within the age range covered (4-12 years). School type, being used as a proxy for socioeconomic information, indicates that children from designated 'disadvantaged' urban schools enjoy a higher-than-average possession of most forms of technology, with the exception of computers and the Internet; however, judging by the presence of TVs, VCRs and DVDs technologies in the child's own room, their ownership levels tended to be higher than average, even in relation to computers and the Internet. When asked about what they would like to receive for Christmas or their next birthday, children appear to desire more technology-based devices, particularly girls. About half of the children surveyed said they use the Internet at home, although older children were twice as likely to do so compared to children from the younger group.

Active pursuits, such as sports, retain great appeal for most children. Playing outdoors was rated highly by children in the focus groups. Board games and table games (e.g. pool) were named as indoor pursuits. There was a mixed response to reading, while playing with animals was mentioned occasionally. Shopping was named in the questionnaires by more girls than boys, mostly from the older age group, and was raised briefly in a focus group.

Television is by far the most prevalent of the technologies used for entertainment. Comedies and other light entertainment programmes are favoured by children. Interest in sports broadcasts is also quite high, especially with boys. Some children, girls in particular, also found 'horror' to be fun — they liked the thought of being scared. 
Although many households have general rules about homework before leisure or time limits on consumption, many children said that there were few rules, if any, about what they watched on TV or played on games machines. Some children with TVs in their bedrooms admitted to disobeying turn-off times.

Mobile phones appear to be increasingly desirable devices as a child gets older. Girls tend to dominate this area slightly and most children said that their main use was to text friends or to play games.

Console games are widely popular. Both genders and all ages said that they played these games, although boys appear to play more than girls. Console gaming appears to increase with age. The frequency and duration of play varies according to factors such as mood, possession of a new game and the weather. PlayStation is the dominant format and most children like the social aspect of playing against each other and discussing or swapping games. Games based on racing and sport appear to be the most popular. Some children like puzzle or quest-style games, although others find them frustrating. The Sims series was widely popular. Action and adventure games were also widely discussed. Most children had seen or played Grand Theft Auto San Andreas (a new, over-18s release at the time). Usually described as 'fun', some children explained that the violence in 'killing' games was not real and that the main objective was to reach a high score or 'beat' the game.

When discussing Internet use, the children displayed a high level of awareness of safety issues. They spoke about protecting their identities online, described the need to withhold personal information and talked about the danger of being taken in by other people in chat rooms. Some children also talked about their role in the household as someone who understands technology - teaching parents or carers on how to use a mobile phone or control a games console.

The majority of teachers and parents were against children having technologies such as TVs or computers in their bedrooms. Teachers were more vocally opposed on the grounds of impact on classroom behaviour or performance. Other adults expressed some reservations, although parents were more inclined to admit some advantages (e.g. when a child is ill or to reduce household conflict about viewing). All agreed that parental supervision was important. Parents felt that technology was a 'huge' part of their children's lifestyles. Some also expressed a concern that it was more difficult to persuade their sons away from technology (especially consoles) than their daughters.

Teachers appeared to be more concerned than parents about the level of mobile phone ownership among the children at school. As with parents, they expressed opinions that technology was very central to children's lives these days, one teacher describing it as 'a mixed blessing'. One concern was about children becoming lazy, mentally as well as physically. Moderation, balance and parental supervision were the key factors identified by several teachers. Teachers were especially aware of the issues surrounding the appropriateness of content that children consume or are exposed to, as well as the contexts in which children experience such exposure.

A number of important issues for future research emerged from the study, including:

- The extent of the generational 'digital divide' between children and adults in relation to technology. 
- Factors governing children's access to and use of outdoor play opportunities. Are children's consumer interests related to a lack of other suitable outdoor venues for socialising?

- The need for critical media literacy skills for children in their engagement with media content.

- The age at which an increasing affinity with technology takes place. Who are the key influencers and how does learning about technology occur?

- The relationship between socio-economic status and the ownership, access and use of technology.

\section{Key policy implications}

- The strategic objectives of the National Play Policy, in particular Objectives 3 and 4, coincide with children's stated preference for outdoor, active play. Further engagement with older children, particularly girls, may be necessary.

- The relatively low public awareness of the statutory and non-statutory regulatory frameworks in Ireland needs to be addressed.

- Adequate resourcing of technology in schools is an urgent requirement.

- There is a major requirement for carefully designed information packages about information and communication technologies (ICTs) for parents, teachers and others working with children.

- A greater emphasis is essential at a policy level to the potential of technology to enrich children's development. What is important is the context in which technology is understood and the vision for realising its benefits in education, recreation and social life. 


\section{Introduction}

The traditional setting for children's play has undergone major change in recent years as a result of the rapid diffusion of technology through all areas of social life. The impact of new technologies on children's play activities - whether in terms of toys that are derived from developments in technology or the leisure activities associated with information and communication technologies (ICTs) — has created a multimedia environment, full of rich opportunities and sometimes dangerous threats (Buckingham, 2000).

This report draws on the findings of a research study of play and technology conducted by the Centre for Social and Educational Research, Dublin Institute of Technology, and presented to the National Children's Office in July 2005. Through interviews and focus groups, this study talked directly to Irish primary school children about the use and influence of technology in their play.

The aim of the research was to explore how much technology impacts on the play activities of children in Ireland and what, broadly, children are saying about the role of technology in their lives. The research investigated the play activities of two age groups (4-8 year-olds and 8-12 year-olds) and explored what technology in play meant for them. The views of parents and teachers were also sought as part of the research. The study was carried out between July 2004 and January 2005.

The main objectives of the research were:

- to identify the kinds of technologies present in the daily lives of children in Ireland;

- to identify the principal patterns of technology use by children within the age groups represented in the study;

- to examine the extent to which technology features in children's everyday play;

- to investigate whether there are significant geographic and social differences in children's use of technology;

- to examine what technology and play means to children, parents and teachers;

- to make recommendations on how children's perspectives might have a role in informing policy in relation to play and technology.

\section{Research sample}

The research involved a survey and focus groups with 292 children between the ages of 4 and 12 years in 10 primary schools from all over Ireland. The sample was a purposive one and is not nationally representative. Of the survey sample, 139 children (almost 48\%) were in the younger age group (4-8 years) and the remaining 153 children were in the older age group (8-12 years).

Girls and boys were represented in the study and some aspects of gender differentiation were explored. Almost $45 \%$ of the respondents (131) were girls. In terms of family position, over $90 \%$ of the children had one or more siblings. The majority of the children (38.4\%) surveyed were the youngest child in their families; slightly over $30 \%$ were the eldest child and almost $23 \%$ were in the middle. $8.6 \%$ of the sample were only children, i.e. with no siblings. 
Participants were recruited from 10 primary schools in various parts of the country. The sample obtained was intended to reflect urban, rural, gender and socio-economic variations, and the means of achieving this was through ensuring a balance of school types. In total, just over $41 \%$ of the respondents (120) were children from a city environment and 172 were children from rural backgrounds. Children identified as 'rurally based' are from households based in small towns and villages, as well as households in the countryside.

Schools were selected to mirror national population trends (see Table 1). Of the 10 schools selected, 4 of them were in Dublin city and one in Cork; one was in a fastgrowing town in Dublin's growing commuter belt; 3 were in or close to moderately sized rural towns; and one was in a small country village that has suffered significant rural depopulation in the last 25 years. In addition to these urban/rural locations, other criteria were applied: one urban and one rural school in the sample were also Irish-speaking (Gaelscoileanna); one urban school was also a private fee-paying school; one urban school was also a multi-denominational school; and two of the urban schools had designated 'disadvantaged' status.

\section{Table 1: Types of schools participating in study}

\begin{tabular}{|c|c|c|}
\hline Name & Type & Description \\
\hline School 1 & Rural & $\begin{array}{l}\text { Rural, outside small town. Area is growing in population, with increasing new } \\
\text { Irish migrant communities in recent years. }\end{array}$ \\
\hline School 2 & Rural & $\begin{array}{l}\text { Rural, in fast-growing commuter town. The town has experienced massive } \\
\text { population growth and urbanisation in the last decade. }\end{array}$ \\
\hline School 3 & Urban & $\begin{array}{l}\text { Urban, Gaelscoil, accommodating students from diverse backgrounds, though } \\
\text { predominantly from higher income families. }\end{array}$ \\
\hline School 4 & Urban & $\begin{array}{l}\text { Urban, designated 'disadvantaged'. Located in a central city neighbourhood, } \\
\text { the school has a majority of students from non-traditional households and lower } \\
\text { income groups. }\end{array}$ \\
\hline School 5 & Rural & $\begin{array}{l}\text { Rural, in small town, located in a village within easy reach of a city with a } \\
\text { predominantly middle-class population. }\end{array}$ \\
\hline School 6 & Rural & $\begin{array}{l}\text { Rural, Gaelscoil, located within a busy market town, with a large rural } \\
\text { hinterland. }\end{array}$ \\
\hline School 7 & Rural & $\begin{array}{l}\text { Rural, in village, located in a small village, dependent on agriculture and in an } \\
\text { area experiencing depopulation and decreasing income. }\end{array}$ \\
\hline School 8 & Urban & $\begin{array}{l}\text { Urban, multi-denominational. Located in a central city area, the school } \\
\text { accommodates a wide range of children from traditional and non-traditional } \\
\text { households. }\end{array}$ \\
\hline School 9 & Urban & $\begin{array}{l}\text { Urban, designated 'disadvantaged'. Located in a central city neighbourhood, } \\
\text { this area has high levels of unemployment, low income, and non-traditional } \\
\text { families. }\end{array}$ \\
\hline School 10 & Urban & Urban, private fee-paying, located in a prosperous suburb of a large city. \\
\hline
\end{tabular}

For the purpose of analysis, school designation is taken as a broad indicator or proxy of socio-economic status. It is acknowledged, however, that many schools have a mixed population and limited inferences are made on the basis of school type, principally in relation to diffusion of technology and the presence, or otherwise, of a digital divide. 


\section{Research methods}

The research used a combination of quantitative and qualitative methods. A questionnaire was used to collect baseline information on access to and use of technology by children. The use of open questions also gave children the opportunity to express their own interests and priorities.

Questions focused on the following:

- General family background - does an older sibling influence the likelihood of certain technologies being present in the home?

- What kind of play do children like, both with friends and alone?

- What kind of technology do children have access to at home and where is it located? Is a 'bedroom culture' emerging in Ireland?

- If children play computer or console games, where do they play and with whom?

- Do children use the Internet and for what?

- What do children like about playing? (addressed to the older, 8-12 age group)

- What kinds of toys and playthings would children really like, for example, as Christmas or birthday presents?

For the purpose of the survey, a broad definition of 'technology' was used, incorporating a spectrum from applied scientific devices or tools used in leisure and play contexts to information and communication technologies (ICTs). The questionnaire included reference to such technologies as tape recorders, cameras, television, musical instruments, computers, mobile phones and games devices (see Appendix 1 and 2).

Focus groups were held with children from the older age group (8-12 years) in order to engage with them on their own views of technology and play. Discussions, led by a moderator, with children in groups of six in each of the schools covered topics about play in general, their use of all forms of technology (including mobile phones, computers and video games) and what they felt was most important to them in playing alone or with friends.

While the research centred on children's perspectives and giving children a voice, teachers and parents were also interviewed for the research. A teacher in each of the participating schools was interviewed during the research. Parents were also given the opportunity to respond and those interested in contributing their views were interviewed either in person or by telephone.

General questions raised in this part of the research included:

- What is the perception of how children spend their leisure time?

- What is the adult's own experience of technology?

- What kind of role or influence does technology have in play?

Questions specific to teachers included:

- What kind of access to technology exists at the school?

- What is the perception of child ownership of technology?

- Do teachers feel differently about technology when they are also parents? 
Questions specific to parents included:

- What differences do parents see in how their children play compared to their own experience?

- What sources of information do parents use for technology/tech-based toys?

- What do parents look for in purchasing games, DVDs, CDs?

- How useful are ratings systems?

The survey data were coded and analysed, particularly against the key variables of age, gender, location and school type. Qualitative data from the responses to open questions and the focus groups were also coded and a content analysis undertaken. Given the focus of the survey on technology in play, particular emphasis was placed on entertainment technology and ICTs in terms of response classification and analysis.

\section{Data collection}

Fieldwork was conducted during November and December 2004. Two researchers were involved in visiting each of the schools, normally spending a day in each location. The process consisted of working with the younger children first (4-8 year-olds) in groups of 2-3 at a time, helping them to complete the questionnaires at their own pace. This was followed by working with the older group (8-12 year-olds), who mostly filled out the questionnaires on their own. Finally, the researchers conducted the focus groups, which involved children from the older group discussing issues about their favourite TV programmes and rules about watching TV and playing on computer or console games. Children also spoke about their use of mobile phones, the Internet and listening to music. Most were very enthusiastic in their responses and in sharing their opinions, even if it meant disagreeing with their peers.

\section{Access, consent and ethical considerations}

Permission was sought from the Principals and Boards of Management of the participating schools. Information packs were distributed to schools and included a letter explaining the background to the project for parents, as well as parental consent forms. Teachers in the participating schools made the selection of children for whom parental consent had been received. Some schools allocated a particular number to each class group; others made the selection based on their own criteria.

Children were also afforded the opportunity to give their consent to participate in the survey. Before each child was given the questionnaire, he or she was supplied with a form to sign, agreeing to be part of the survey. This was titled the 'Child Consent Form', although technically it was assent rather than consent they granted.

Anonymity was afforded all children in the research and no identifying feature, other than the school type, is recorded in the database. Schools are not identified in the report and only their general location is referred to. 


\section{Review of literature on children, play and technology}

While considered an important aspect of development for us all, play has a central role in the development of children. Play is recognised as a critical process in childhood, closely related to development. Notwithstanding extensive and varied attention, the mechanisms through which play influences development are not well understood (Bruner et al, 1976; Smith, 1986; Sutton-Smith, 1997).

Play is identified as the process through which many key skills are developed and through which imagination and creativity find expression. Through play, children develop the social skills necessary to negotiate their widening world, the problem-solving strategies that facilitate school and life success. Play affords a means of checking theories, exploring options, testing limits and fostering social and relational skills. It is characterised by common features, including pleasure, spontaneity and intrinsic motivation, and is a natural form of learning. Play can be individual or social, and is the process whereby children find the opportunity to exercise freedom of choice (Garvey, 1990; Bruner, 1996; Moyles, 1994; McArdle, 2001). Notwithstanding its central relationship with development, children's play is often trivialised as something to do when not working, something to occupy children and 'keep them off the streets'.

The increasing use of technology by society at all levels has prompted investigation into its application in education and its deveopmental benefits in particular. Recognising that learning is an active process and that children learn better 'by doing' than by being told, educationalists have realised the potential contribution of interactive technologies to education (Papert, 2005). Children use technology to make complex and intellectually rich constructions, and a wide range of programs have been developed to challenge their thinking and imagination towards improving literacy, numeracy and general problemsolving skills.

\section{Technology, play and development}

Play has been defined as the 'freely chosen, personally directed, intrinsically motivated behaviour that actively engages the child' (NCO, 2004, p.10). It is regarded as a central policy focus for Ireland's National Children's Strategy, emerging as a key concern for children themselves in the consultations undertaken with children prior to the final publication of that strategy (Department of Health and Children, 2000).

The aspect of play under consideration in this research is technologically mediated activity and the influence of ICT on children's play. It has been argued that the development of ICT has not only influenced the form of play, but has also brought play, as a concept, more visibly into the lives of older children (Sheridan and PramlingSamuelsson, 2003). This has arisen in particular due to increased availability of the computer and associated games and educational programs. Livingstone (2002) enters a long-standing and familiar debate when she asks whether the computer is best thought of as a toy or a tool, whether play is part of, or opposed to, learning (Sheridan and PramlingSamuelsson, 2003; Sutton-Smith, 1997). Whatever one's position, there is agreement that 
the process of play is important to development and shares many features with learning — features that remain despite altered contexts and contents.

Fleming (1996) has argued that the toys children play with — whether they be My Little Pony, Lego or Nintendo - help them make sense of their worlds and are essential to their development. Unquestionably, toys are increasingly products of a globalised consumer culture, but in children's hands, Fleming suggests, children have the capacity to escape the stereotypes of gender and power that these toys sometimes apparently produce. Similarly, the study by Dyson (1997) of children's story-making, using superheroes and characters drawn from the media, suggests that these act as a prism in which images of power and gender are translated into children's worlds, rendering them more complex and helping them deal with the contradictory pressures of growing up in a multicultural society.

Tapscott (1999) concurs and suggests that the technological world in which children are growing up is beneficial to their development: 'Digital media is creating an environment where such activities of childhood are changing dramatically and may, for better or worse, accelerate child development. Child development is concerned with the evolution of motor skills, language skills and social skills. It also involves the development of cognition, intelligence, reasoning, personality and through adolescence the creation of autonomy, a sense of self and values ... All of these are enhanced in an interactive world. When children control their media, rather than passively observe, they develop faster.'

Wartella (2002) has similarly argued that the many positive behavioural features described by Tapscott (1999) are actively displayed in children's online and digital experiences and their enthusiastic displays of interactivity and playfulness offer enormous potential. However, such interaction needs to be carefully analysed and harnessed if its benefits are to be realised. While the view of the communicative and educational possibilities of the digital age offered by its many believers is an avowedly optimistic and sometimes highly uncritical one, Buckingham (2000) advocates that we do not dismiss it out of hand.

The many attributes and values of creativity, spontaneity and the potential for learning receive strong endorsement in such accounts and provide a strong counter-current to what is often seen as the dominant negative assessment of how technology has affected children's lives in the so-called 'effects tradition' of research. Technology provides new opportunities for children in play by way of both content and tools. Technology can extend play rather than usurp it and can provide opportunities that facilitate children developing new ways of playing, communicating, thinking and knowing.

\section{Technology's impact on development}

Elkind (2003) challenges too simplistic an approach to investigating the impact of technology on children's overall development. He argues that researchers have been somewhat limited in their approach to this issue by concentrating on the impact of particular technologies when they ought to be considering the impact on children's development of growing up in a technological environment. Features of this environment are what matter and it is through understanding these that researchers can focus on what impacts there may be. He identifies a number of features of this new culture: it is speed- 
dominated, screen-based, information-focused and a communication culture. 'Digital children', as he characterises this generation of Western children, may be growing up disconnected from adults - teachers and parents alike. They are more advanced in their capabilities with technology and more responsive and flexible to new developments.

There are potentials and challenges to be considered. Such a culture will influence the language and concepts that children learn. The concepts of space and time have been altered by technology. Elkind (2003) suggests that the focus on speed that the developing technologies have brought to education and other aspects of society has created a hurried society where children may feel guilty about taking time off to play. Over the last 20 years, children in the USA have lost 12 hours of free time a week and 8 of those lost hours were once spent in unstructured play and outdoor pastimes (Elkind, 2003). It is possible that the critical features of development acquired through more traditional, unstructured play may well be acquired through the medium of technology, but as yet there has been limited research into this aspect of the technological world.

Experts are divided as to the value of technolgy to development. While some argue that it enhances intellectual development and fine-tunes a wide range of skills, others are more sceptical and are concerned that it limits social and linguistic interactions, constrains brain development by prescribing the parameters within which children operate and directly influences negative behaviours (Attewell et al, 2003; Gentile, 2003).

Exemplifying some of the 1990s' optimism that surrounded the growth of the Internet, a number of commentators (e.g. Tapscott, 1999; Rushkoff; 1999; Papert, 1993 and 1996; Katz, 1996) celebrated the arrival of the 'Net Generation' — a distinct generation with inherent and spontaneous ability to navigate the digital world, who learn to communicate, work, shop and play in profoundly new ways, are incredibly technically aware and leave their parents far behind in the adoption and use of new technology.

Quick to respond to the changing climate, the toy industry has identified children as a key consumer group. Even the very youngest children are a potential market, exemplified by the development of 'lapware' and 'infantware' as 'educational' toys for parents. Such developments have been criticised by developmental researchers, who point out that many manufacturers have a limited sense of the developmental paths that children follow or pedagogical understanding of the way children learn (Elkind, 1998; Healy, 1998; Buckingham and Scanlon, 2002). Hohman (1998) observes that many of the skills that these new software programs are designed to enhance (e.g. fine motor skills) are best developed through more informal and social opportunities, such as finger-painting, fruitpicking and sorting various materials. Haugland (2000) considers screen-based technologies to be developmentally inappropriate for younger children given the extent to which we understand the importance of active participation in learning for young children. The close interaction with adults and peers evident in traditional play is considered missing in play through technology and opportunities for conversation and dialogue, critical in early development, may therefore be limited.

While the educational applications of ICTs have received strong parental support and the investment in a home computer is frequently justified as an investment in the future, actual usage does not always follow through. In the USA, following a three-year qualitative investigation, Giacquinta et al (1994) concluded, not surprisingly, that most children use computers to play games and that the educational promise of technology could only be realised with strong parental supervision and close liaison with schools. 
Bruckman (1999) points out that the widespread enthusiasm for ICT in education has not been matched by research and that our understanding of the pedagogical role and value of the computer lags seriously behind. The models of technology-based learning in use have also been criticised and Buckingham and Scanlon (2001 and 2002), who suggest that the pedagogic strategies of 'edutainment' in children's information books, pre-school magazines and CD-ROMs are informed by a reductive and disciplinary conception of learning, combined with an apparently contradictory emphasis on entertainment and 'fun'.

In its leisure manifestations, technology - whether it involves playing games, surfing the net or instant messaging - is closely associated with the young. There is an implicit assumption that growing up in the digital world involves a whole new set of media literacies or competencies, which include new orientations to learning, communication and social interaction. Hence, what Buckingham (2000) refers to as the 'new generational rhetoric' represents an idealistic image of children in the digital age, the first generation to benefit from growing up with computers, the Internet and video games.

\section{Negative impact of technology}

There is within the literature a substantial, though frequently inconclusive, body of work about the negative impact of technology on child development. Whether from the point of view of exposure to inappropriate content or the effects of technology use on health or lifestyle, a substantial body of research places technology in a negative, determinist fashion. Concern is also often raised about whether major corporate interests in technology exploit children's innocence and if children's play opportunities have become an extension to global consumer culture. In addition, there are major policy implications concerning child health, safety and well-being in relation to children's use of existing and emerging technological platforms.

The view that technology is destructive of childhood is frequently mentioned in both academic and popular discourse. Ever since Postman's classic text on The Disappearance of Childhood (1994), a number of social commentators (Winn, 1977 and 1984; Elkind, 1988; Meyrowitz, 1985; Tobin, 1998) have raised major concerns about the impact of electronic media on social life and how it has eroded the line between childhood and adulthood.

An area that attracts a great deal of attention and controversy is the topic of children's exposure to inappropriate content, sex and violence through computer games, videos or television. Reflecting on the role that violence plays in media entertainment and why viewers are drawn to it, Goldstein (2000) argues that the audience relationship is a complex, multilayered one that needs to be studied in context. For example, a study of Danish children aged 5-17 argues that the widespread practice of playing 'violent' computer games should be seen as a form of virtualisation of the real world of play, a parallel to the rough-and-tumble play traditionally found among boys (Sorensen Holmes and Jessen, 2000). From the perspective that video games are now simply an accepted part of children's culture, Fromme (2003) argues that there is no evidence to suggest that children's gaming culture is necessarily damaging; he found that children who are quite engaged, in terms of frequency and general interest in playing computer games, apparently do not give up other activities and interests, like outdoor and sport activities. 
What is required to support positive outcomes for children, Fromme concludes, is positive parental involvement, engagement and interaction in children's gaming culture.

Children's emotional responses to television, video or computer games, and their effects on children's imaginations are another important theme in effects studies (Valkenburg, 2004). Asking whether screen media stimulate or constrain children's imaginative responses, their story-making and their ability to creative imaginary play worlds, Belton (2001) argues that the ubiquity and ease of access to television and videos does have implications for the development of children's imaginative capacity by constantly demanding responses to external agendas. Others have argued, however, that new media, particularly educational applications using adventure or fantasy role-playing games, can foster imagination and encourage children's creative capacities (Valkenburg and Cantor, 2001). Research in this area, however, remains incomplete and inconclusive.

\section{How children use technology}

Alongside the debates on the developmental and social impact of technology, increasing attention is being given to the different contexts in which children have access to technology in their lives, the patterns of adoption and the role of factors such as age, gender and socio-economic class. Children's access to technology and openness to media influence is, in the first instance, mediated by parents and regulated by decisions made in the context of family relationships and the use of media and ICTs. Seiter (1999) illustrates how cultural capital and 'lay theories of media effects' play a major role in how parents negotiate and seek to maintain a particular relationship with the broader media environment. Similarly, Hoover et al (2004) found that there are differences in the way families define a sense of their media identity and attempt to establish distinct normative positions on contemporary media culture, ranging from the oppositional to fully integrationist.

Large-scale national surveys on the use of technology, as well as detailed qualitative and ethnographic studies, provide identifiable trends and informative insights into the extent and place of technology in childhood (Livingstone and Bovill, 1999). Specific aspects of children's adoption of technology, such as mobile and online communications as well as electronic gaming among young people, have received particular attention.

A recent review of childhood in Ireland found that outdoor activity and socialising still rank high in chosen pursuits of Irish children (Devine et al, 2004), with $48 \%$ of school children taking physical exercise four or more times a week (National Health and Lifestyle Surveys, 2003). Participation in organised play activity (e.g. sports, dance and arts programmes) is influenced by gender, location, social class and costs, where applicable (Whyte, 1995; Brennan, 2001; Daly and Leonard, 2002). Research also indicates that $90 \%$ of children surveyed aged 10-14 had access to their own mobile phones and video players, while $81 \%$ had access to cable TV and $78 \%$ had access to a DVD player (Internet Advisory Board, 2004). About one-third of children reported having access to cable TV in their bedrooms, although only a very small number have access to the Internet in their bedrooms (3\%).

Similar findings have been found in research in the USA (Roberts, 1999 and 2000) and in Denmark (Christensen and Tufte, 2001). Television remains the dominant medium and is 
typically characterised by several TV sets in the household and individualised viewing patterns. Radio features much less, but music is clearly important to young people. Internet access has impacted on patterns of interaction and activity in family media use and is reported as a frequent source of friction. Mobile phones are widely used by young people and are an expression of a new culture of conversation and social interaction. A study of Irish primary school children, carried out by the Irish National Teachers Organisation (INTO), found that $96 \%$ owned a mobile phone, which was used $81 \%$ of the time for texting and 20\% for making calls (Irish Times, 2006).

There are also gender differences evident in technology ownership and use. Boys of middle-class origin are the archetypal early adopters of new technology, while girls everywhere are less likely to own media apart from books. In particular, girls are less interested and involved in computers, and less likely to have access to a computer in the home (Livingstone and Bovill, 2001a). The diverging media interests of boys and girls is reported in the American study by Wright et al (2001), who found that older boys spent more time watching sports and playing electronic sports games, while older girls spent more time watching relationship dramas and not a great deal of time playing video games (in part due to the lack of availability of appropriate electronic games for older girls). This age and gender pattern was also found in Brennan's study of children's use of free time (Brennan, 2001).

Access to computers and the Internet in schools has been dramatically improved by the targeted investment of the Department of Education and Science through the schools' IT2000 Programme. A review of the programme found that the ratio of pupil to computer was 19.6:1 at primary school level, with $79 \%$ of primary pupils having some access to the Internet (NPADC, 2001).

Research on the role of technology in children's lives is a relatively recent phenomenon. The literature on the topic now draws on diverse interests and traditions of research in children's studies, the sociology of childhood, developmental psychology, communications studies and education, as well as expanding field of research on technology and society. While there has been a long-standing interest in the role and impact of the media on children, the focus on technology as such and how it is used by children represents a new direction in recent academic research. As a research question, it has played an active role in contributing to many policy debates on questions of child safety and well-being in the context of new technology and issues of adult awareness of the opportunities and dangers provided by ICTs. However, what emerges time and again is the need for more information and more data about children's access to technology, how they use what is available to them and what technology use means to them. 


\section{$3 \quad$ Play and technology for children, aged 4-12}

One of the main questions for this research was to explore how technology impacts on children's play in Ireland. The research sets out to identify what kind of technology children access on a daily basis and how pervasive is technology in the home and in play activities with friends, as well as for solo leisure.

As part of this research, a survey was conducted in November and December 2004 among approximately 300 children, aged 4-12, from a variety of urban, rural, State and private schools (see Chapter 1 for details of survey sample and methods). The findings provide a snapshot of the extent and range of technology available to children, with baseline data about children's access to technology within the home, their favourite leisure activities, their interest in computer and console gaming, and the context in which such play occurs. Data about Internet use and areas of interest on the web are also included. In addition, focus group discussions helped to probe more deeply into children's experience and interests in the use of media and technology in their leisure time.

\section{Play activities}

Children were first asked to list their three favourite play activities, both when playing with friends and when they were on their own (see Figure 1).

\section{Figure 1: Favourite play activities (\%)}

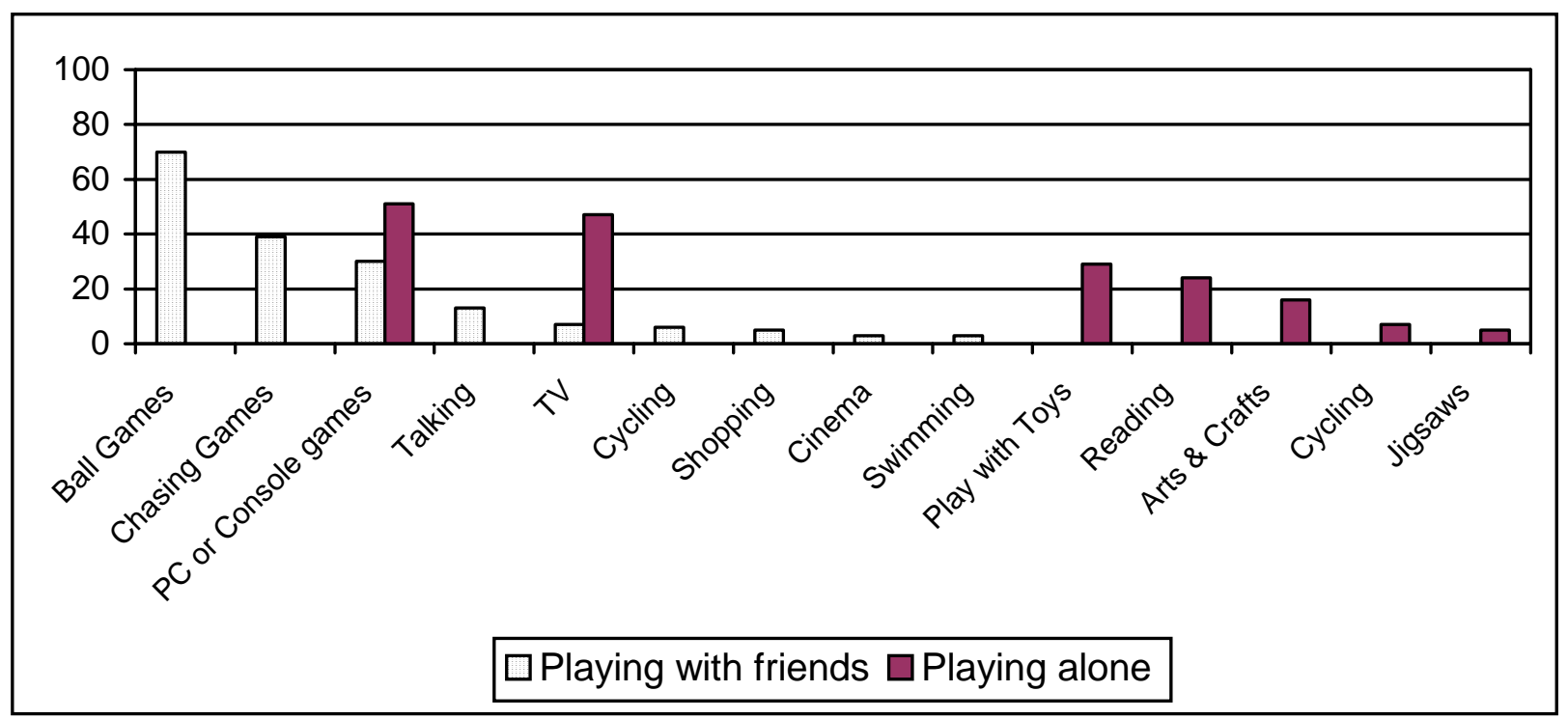

What stands out from the children's responses is that outdoor activity-based play with friends (such as ball games and team sports, chasing games) is more highly valued by children than any other activity. Playing computer and console games and watching TV are also popular, as is just talking, suggesting that children favour the kinds of activities that involve a good degree of interaction, or potential for discussion, with their playmates. 
By far the most popular activity listed by the children when playing with friends is playing football and other ball games. 70\% of children included this category: more boys than girls, and more rural-based children than urban-based ones. For children in the younger age group, chasing games are the most popular with girls and boys alike. Other active pursuits, such as cycling and swimming, are also listed.

Talking is also frequently cited as a favourite social activity, particularly among older children, especially girls. Shopping is listed as another favourite leisure activity, particularly among girls. Music does not feature prominently in this age group and had a relatively low occurrence.

Screen and technology-based play, such as playing PC or console games, is listed by nearly one-third of the children, after football and chasing games. It is more popular with older boys and with rural-based children. Among older children, watching TV is also a popular technology-based activity. Some other media-based activities listed included going to the cinema and texting, mentioned exclusively here by girls in the older age group.

When it comes to playing alone, technology and television become the dominant activities. Playing computer, video or console (including Gameboy) games is the most popular option for children when playing alone. This category also includes references to playing on the computer and Internet in terms of printing out pictures or logging on to child-oriented websites, as well as playing consumer game titles. This response was almost twice as likely to be given by the older children, although a moderate number of younger respondents also gave this answer. Boys gave this response considerably more often than girls, and rural-based children nearly twice as often as children in urban settings.

Watching TV or films (on video or DVD) is also listed by nearly half the children as an activity when playing alone. Responses were evenly represented across all groups girls and boys, urban and rural - and stands in contrast to what children choose to do when there is someone available to play with.

Playing with toys is listed by nearly one-third of children, with a higher proportion in the younger age group. Reading is also included as a pastime for $25 \%$ of the children, compared to over half who included playing computer games.

\section{What children like about playing}

In order to gain a sense of the value placed by children on play and to hear them describe what they liked and enjoyed in their play, the older children in the survey were asked to complete the sentence 'What I like about playing ...'. Some children found the question difficult to answer or said that they did not really know. From the responses obtained, however, it was possible to identify five main themes:

- 'Playing is fun!' - 62 children (over one-third of the older group) mentioned 'fun' in some context. 
- 'Doing what I like!' - 27 children (over one-fifth of the group) specified some form of play activity (i.e. they named a particular activity). 9 children specified PlayStation and another XBox.

- 'Playing with my friends' - 21 children (over one-seventh of the group) mentioned friends, indicating that friendship is an important aspect of play.

- 'To pass the time' - 20 children indicated that it was a good way to pass time and to prevent boredom.

- 'Getting exercise' - 11 children referred to the exercise element and said that it was a good reason to play.

Many of the children value a sense of fun and enjoyment. Two children refer to playing as something they are 'good at'. Several children use phrases that they may have picked up from adults, such as 'being with my friends and playing in peace', 'it gets me out of the house' or '... will keep you amused for hours'. Another child refers to games being shareable, 'on a wet day it's not like a book - you can play it with others'.

Video and computer games get a mention, but the most frequently named of this genre is PlayStation. The range of games available on PlayStation appears to contribute to its appeal - 'you can play any type of games you want'. Another child described computer games as a challenge and three made reference to learning. One child who was a skateboarding enthusiast was well able to articulate why he enjoys this activity 'because there are no rules and you can make up your own moves'.

Although most children see play positively, 20 children related play to boredom — as a means of avoidance, rather than an opportunity.

\section{Information and entertainment media in the home}

Children were asked to indicate what kind of information and entertainment media they had access to at home. Following the broad definition of technology, incorporating a spectrum from technology in leisure and play contexts to information and communication technologies (ICTs), the questionnaire included reference to such technologies as tape recorders, cameras, television, musical instruments, computers, mobile phones and games devices. Traditional forms of media were also included (e.g. books), as well as Internet access.

Children were also asked to indicate if any of these technologies were present in their own rooms (usually their bedrooms). This was to assess the presence, or otherwise, of what Livingstone and Bovill (2001a) have identified as the phenomenon of the 'bedroom culture' or the 'media-rich bedroom', where children have access to possessions that would traditionally have been sited in a family space.

Figure 2 provides an overview of the ownership of information and entertainment media for both urban and rural locations in the survey. Findings highlight the prevalence and wide diffusion of traditional and new media sources across all homes. Books, television, radio, computers and games consoles are found in the vast majority of homes. Internet access, at close to $60 \%$, is well above the national average of $44 \%$ reported Internet usage for the period (ComReg, 2004). 
Figure 2: Media ownership in the home, by location (\%)

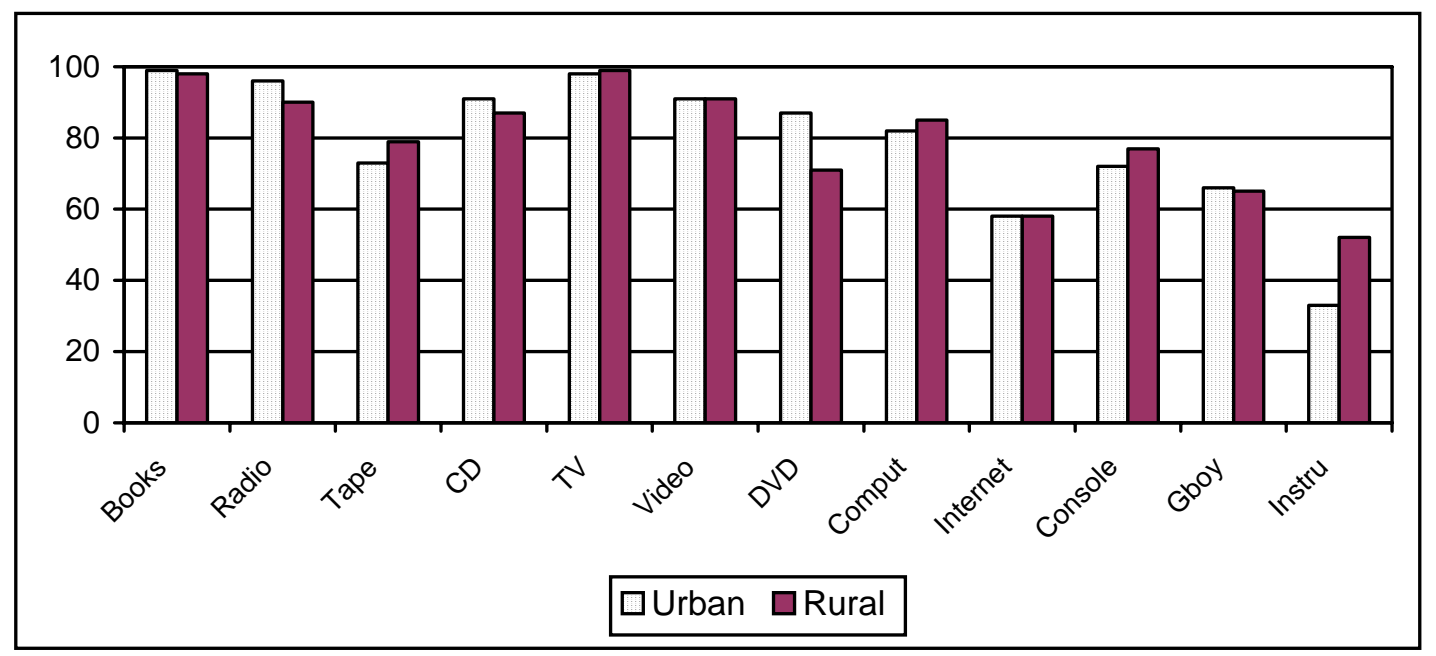

Age is a factor in higher access to screen-based media. Figure 3 illustrates that as children get older they gain increasing levels of access to such technology as games consoles and Gameboys, and report higher levels of access to nearly all categories, including computers, DVD and CD players.

Figure 3: Media ownership in the home, by age group (\%)

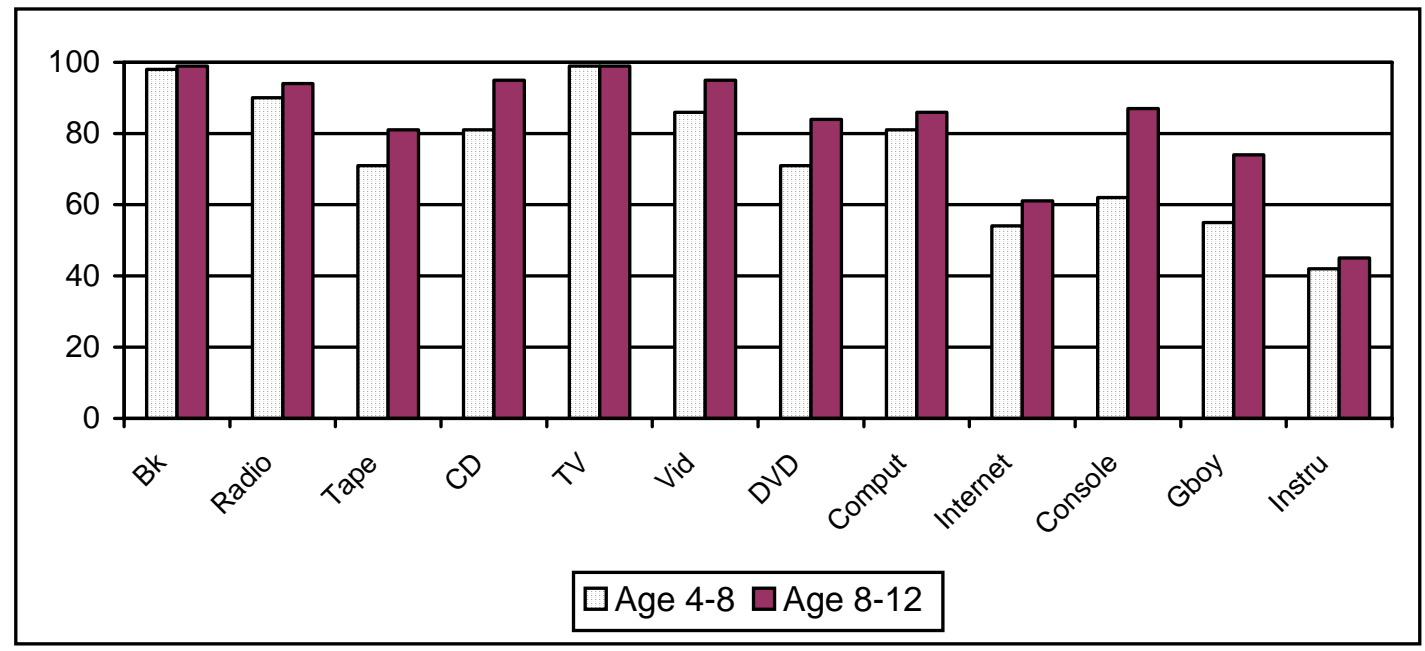

Gender is also a factor with gaming technologies. Figure 4 shows that boys report greater levels of access to games consoles and Gameboys, although not by a very large margin.

Figure 4: Media ownership in the home, by gender (\%) 


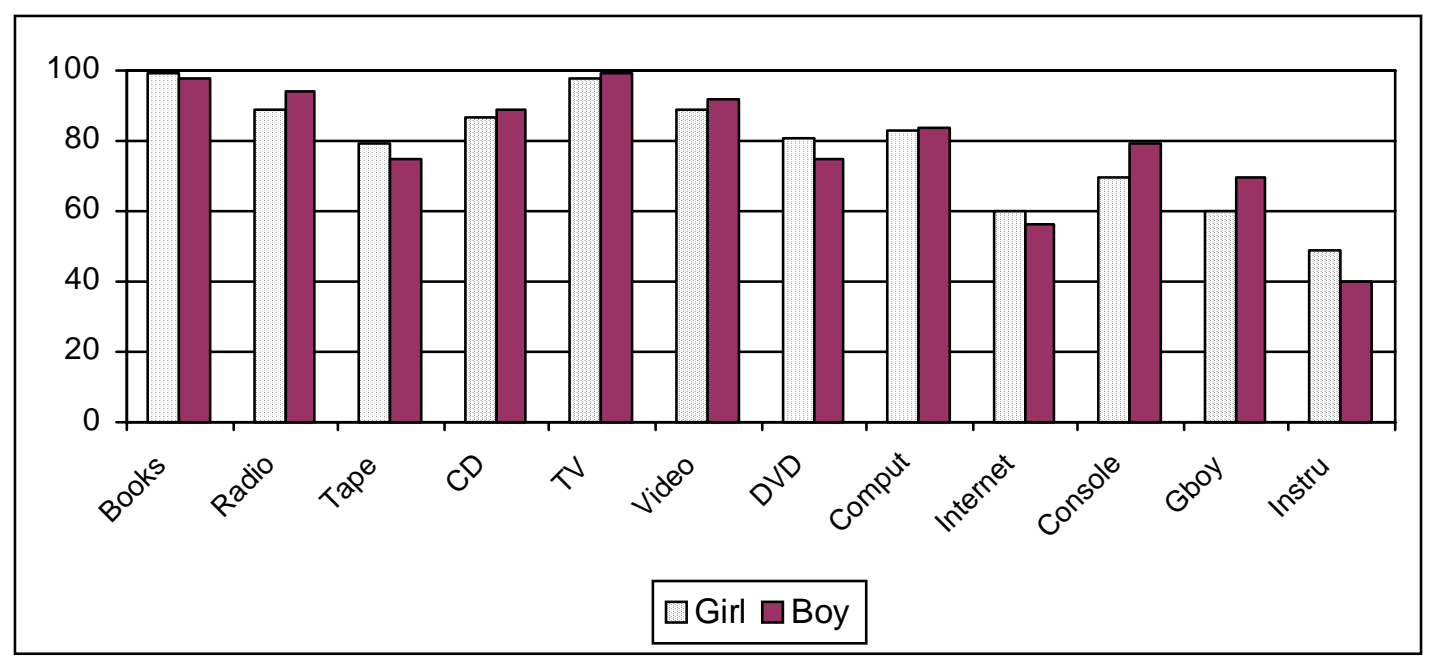

In Figure 5, the existence of a 'bedroom culture' is explored for the two age groups of children in the survey. Books are present in over $80 \%$ of all children's rooms (as well as being present in the homes of children in 6 out of the 10 schools participating). Traditional media, such as radio, TV and CD players, are found in nearly $40 \%$ of children's rooms and games consoles in nearly $30 \%$.

\section{Figure 5: 'Bedroom culture', by age group (\%)}

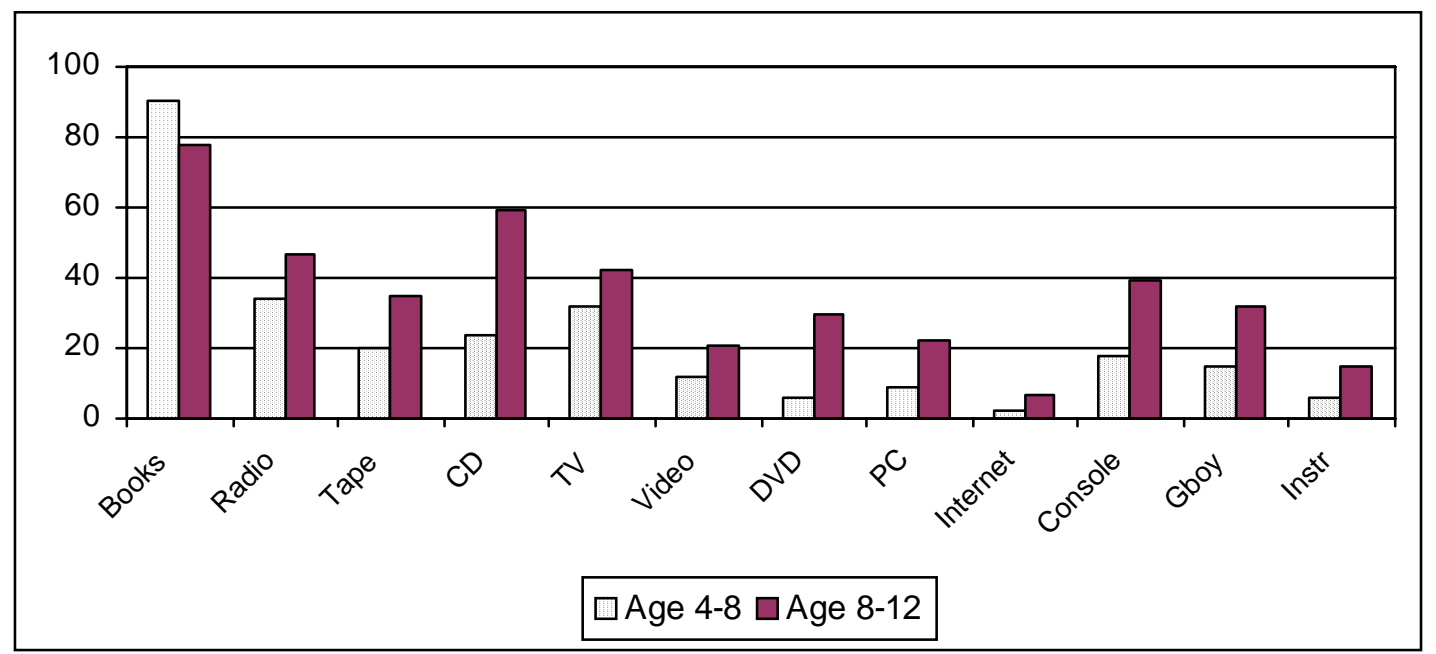

Age is the most critical factor in terms of the rise of what might called the 'media-rich bedroom' and declining levels of reference to books are replaced by a higher presence of music technologies (radio, tape, CD and instruments) and screen-based entertainment, including DVD, video, PC and gaming technologies. Little gender difference was reported in the survey, with girls reporting slightly higher usage of CD players, radio and tape recorders in their own rooms. Again, perhaps counter-intuitively, little gender differentiation was reported in electronic technology, such as TV, DVD or games consoles. 


\section{Screen-based entertainment media}

Developing the topic of screen-based entertainment media, it is clear that TV, games consoles and computers play an important part in children's leisure activities. Practically all children have access to TV and approximately $80 \%$ of children have access to computers and games consoles, half of them in their own rooms. It is their favourite activity when playing on their own and a very popular activity when playing with friends.

Although there was limited opportunity to explore the role of geography and socioeconomic factors in the survey, some clues are provided by the findings for the different school types represented and are worth exploring in further detail.

\section{TV, DVDs and VCRs}

Television and the ancillary technology of DVDs and VCRs represent the mainstay of screen-based entertainment media for children. They are all widely available to children throughout the home and are a centre for play and leisure activity.

Television is almost universally available and, although most children expressed surprise that the question should even be asked, a small number reported that there was no TV in their household. 98.6\% of children confirmed that there was at least one TV in their home. Many children specified how many TVs were in their household and where they were located, although this was not pursued further. Children in 7 of the 10 schools indicated $100 \%$ presence of TV in their homes (see Figure 6). The lowest levels of possession of a TV at home were indicated by children in the Gaelscoileanna (93.3\% urban school and 96.4\% rural school) and in the rural village school (98.2\%).

Of particular interest is the reporting of the presence of a TV in children's own rooms across the different schools. In total, nearly $40 \%$ of all children stated that there was a TV in their bedroom, with a slightly higher proportion for older children and a negligible difference between urban and rural households. Informally, many children said that only Irish TV channels were available on the sets in their bedrooms (rather than cable or satellite connections) and that they were frequently used for playing console games as opposed to viewing TV, a topic that was discussed further in the focus groups.

Figure 6 compares the presence of a TV in the home and in a child's own room across the 10 schools surveyed.

- In 4 of the 10 schools, possession of a TV in the child's own room was between $26 \%$ and $29 \%$ (in the mid-range of the scale).

- Just over $46 \%$ of children in School 2, a rural school in a fast-growing commuter town, reported having a TV in their own rooms.

- The highest levels of having a TV in children's own rooms were reported from Schools 4 and 9, the two designated 'disadvantaged' urban schools, at over $76 \%$ and almost $61 \%$ respectively.

- Children in School 10, a private fee-paying urban school, reported the lowest level of TV in their rooms (under 16\%), followed by School 3, an urban Gaelscoil (under 17\%).

Figure 6: TV in child's own room, by school type (\%) 


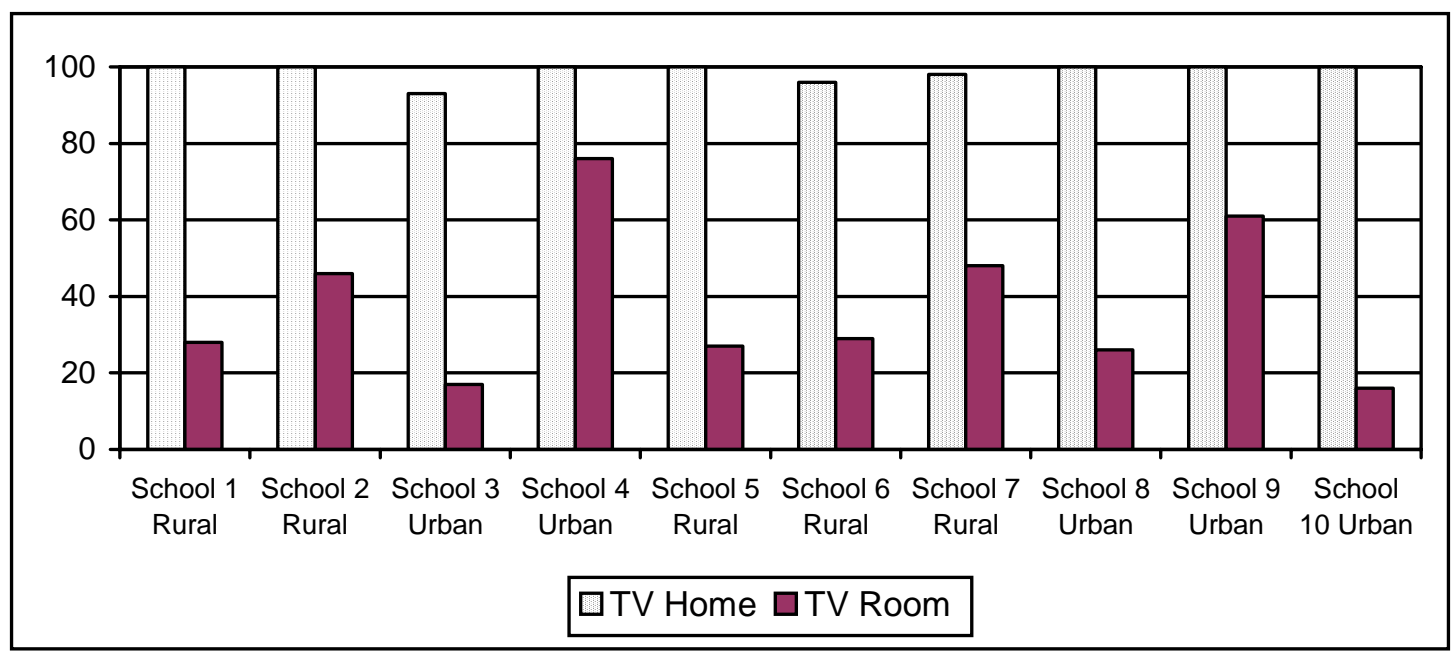

Note: See Table 1 for full description of the 10 school types.

Similar findings were reported for access to video cassette recorders (VCRs) and DVD players in children's own rooms.

The findings for VCRs in children's own rooms were:

- Nearly $17 \%$ of children said that there was a VCR in their room. There was a noticeable difference between the age groups, with over $20 \%$ of older children saying they had a VCR in their room compared to $12 \%$ of younger children.

- The highest level of VCR presence in children's rooms (over 39\%) came from children in School 4, which is designated 'disadvantaged', who also reported the second highest level of VCR presence in their homes.

- The second highest level of VCR presence in children's rooms (over 38\%) came from children in School 9, also designated 'disadvantaged'.

- The lowest level of VCR presence in children's rooms was reported by children from generally better-off backgrounds (urban Gaelscoil, 3.3\%; urban multidenominational school, 7.4\%; urban private school, 10.5\%).

- Possession of VCRs in the children's rooms in the remaining schools ranged from $13.3 \%$ to $19.2 \%$.

As regards DVD players, over three-quarters (77.4\%) of children reported that there was a DVD player in their household. The highest level of having a DVD player in the home (approximately 90\%) was reported by children in one of the designated 'disadvantaged' schools in the survey. Children in School 10, an urban private school, had the second highest level of having a DVD player at home (89.5\%). The lowest levels of owning DVD players in the home were reported by children in rural schools, for example, School 1 , a rural school outside a small country town, at just over $53 \%$. All other schools ranged between $80 \%$ and $88.5 \%$.

The findings for DVD players in children's own rooms were:

- Just under $19 \%$ of children said that they had a DVD player in their own room, noting again that console games machines with DVD capability may also be located in the child's room.

- Children in the older age group were over four times more likely to have a DVD player in their own room (29.6\%) than younger children (6.5\%). The number of 
children responding positively to this question was slightly higher in rural-based households (19.8\%) than in city-based ones (17.5\%). The difference between boys and girls in having a DVD player in their rooms was minor - $19.1 \%$ of girls have one and $18.6 \%$ of boys.

- Children in the designated 'disadvantaged' urban school who indicated high levels of ownership of a DVD player in the home also indicated the highest level of having a DVD player in their rooms (39\%).

- Children from the designated 'disadvantaged' urban school who indicated the highest level of DVD player ownership in the home also indicated the second highest level of having a DVD player in their rooms (28.6\%).

- The lowest level of having a DVD player in children's rooms was indicated by children in an urban Gaelscoil (6.7\%), followed by children in an urban multidenominational school (7.4\%).

- Possession of DVD players in the rooms of children in the remaining schools ranged from $10.5 \%$ to $25 \%$.

\section{Computers and the Internet}

Almost $84 \%$ of all children interviewed said that there was a computer in their home. While the survey did not explore the reasons for having a computer (whether for professional, educational, information and/or entertainment reasons), many children named one or other of their parents as owning one, to which the child sometimes had access.

Just over $86 \%$ of older children and $81 \%$ of younger children reported that they had a computer at home. Possession of a computer is higher in rural areas (85.5\%) than in urban areas (81.7\%). Over $83 \%$ of girls and $84.5 \%$ of boys said there was a computer in their home.

Only $16 \%$ of all children in the survey reported having a computer in their own room. The vast majority of these were from the older age group: over one-fifth of these respondents (almost 22\%) said they had a computer in their room. There was little difference in terms of gender, with $16 \%$ of girls and $15.5 \%$ of boys reporting this. Despite the higher level of owning a computer in rural-based households, children in urban households were a little more likely to have a computer in their own room $-16.7 \%$ of city children said they had one, compared to $15.1 \%$ of rural children.

Figure 7 compares home ownership of a computer and its presence in children's rooms across the 10 schools surveyed. Children in Schools 3 and 10 (an urban Gaelscoil and an urban private school) indicated $100 \%$ home ownership of a computer. The next highest level of home ownership was indicated by children in School 6 (a rural Gaelscoil), at almost 93\%. The lowest levels of owning a computer at home were reported by children in Schools 4 and 9 (the two designated 'disadvantaged' urban schools), at 57.1\% and $69.6 \%$ respectively. Children in all other schools reported home ownership of a computer ranging between $78 \%$ and $86 \%$.

Figure 7: Computers in the home and in child's room, by school type (\%) 


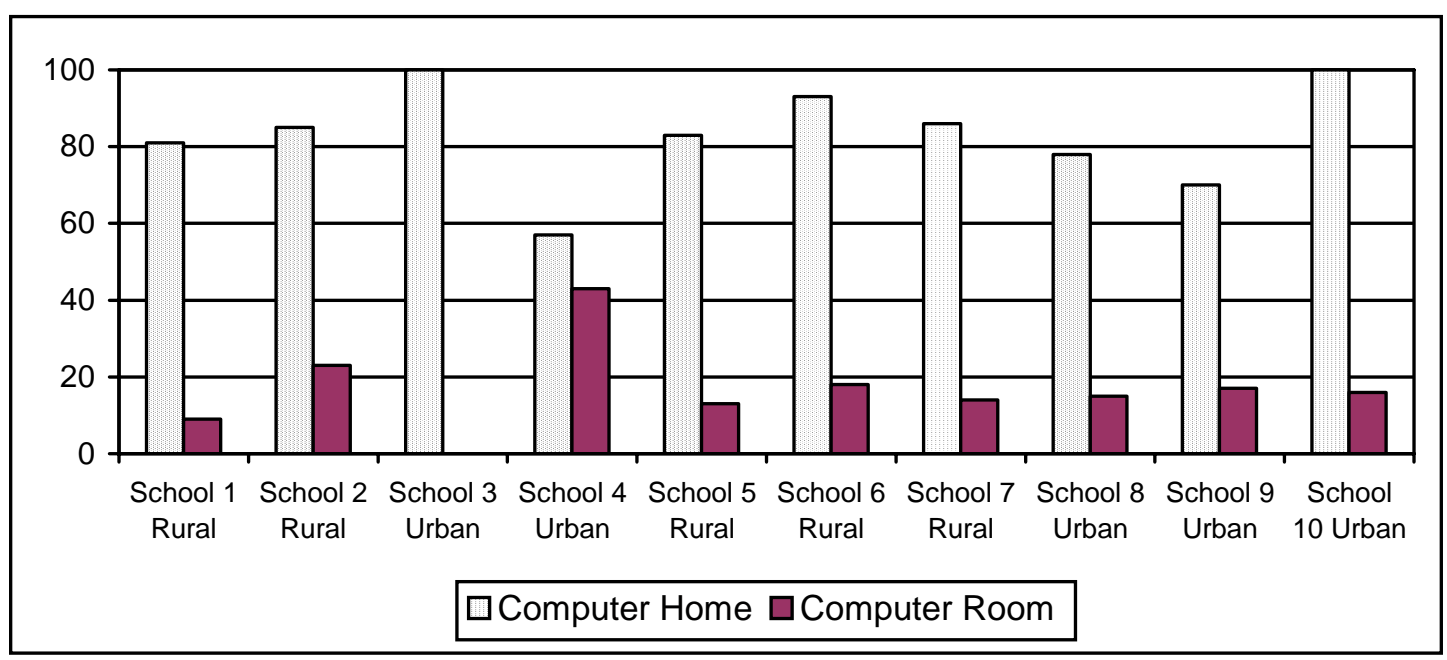

Note: See Table 1 for full description of the 10 school types.

Some interesting findings in relation to computers in children's own rooms were:

- Children from School 4, one of the designated 'disadvantaged' urban schools, who reported the lowest level of home ownership of a computer also indicated the highest level of having a computer in their own rooms, at almost 43\%.

- Children in School 9, the other designated 'disadvantaged' urban school, who had the second lowest level of owning a computer at home also indicated the fourth highest rate of having a computer in their own rooms, at $17.4 \%$.

- Children in School 3, an urban Gaelscoil, reported having no computers at all in their bedrooms, while children in School 1, a rural school, had the second lowest level (9.4\%).

- Possession of computers in the rooms of children in the remaining schools ranged from $13.3 \%$ to $15.8 \%$.

As regards Internet access, almost 58\% of children said there was Internet access in their home. There was only a slight difference between rural and urban homes, with $57.6 \%$ of rural children responding positively and $58.3 \%$ of city children doing so. Older children gave a higher positive response (over 61\%) than younger children (54\%). Girls (over $60 \%$ ) indicated a slightly higher rate of home Internet access than boys (almost 56\%). Only 4\% of children said they had Internet access in their own rooms. Some children, particularly in the younger age group, were not sure whether the computer in their home had Internet access or not.

There is some evidence of a digital divide in the availability of Internet access. Children in School 10, an urban private school, reported the highest level of Internet presence in the home (89.5\%), with children in Schools 3 and 6, both Gaelscoileanna, reporting the next highest rates of Internet presence at home (75\% and 70\% respectively). The lowest level of Internet presence at home (33.3\%) was reported by children in School 4, a designated 'disadvantaged' school, who had also reported the lowest level of home computer ownership (see above). Children in School 7, a rural school in a village suffering depopulation, indicated the second lowest level of home Internet presence, at 37.5\%. Children in School 9, the other designated 'disadvantaged' urban school, reported the next lowest level (43.5\%) of Internet presence at home. Children in all other schools reported home Internet presence ranging from $55.6 \%$ to $66.7 \%$. 
Computers and the Internet are therefore a growing feature for children's leisure time in Ireland, with widespread availability at home and increasing levels of Internet usage. There is evidence of a digital divide and uneven availability of both computers and Internet access. This is a rapidly changing area, however, and further research into children's use of computers is needed.

\section{Gaming technologies}

Gaming technologies and games consoles are hugely popular among all Irish children and are widely available to all. It is clear that they are used differently among the groups surveyed here, but they represent one of the most visible aspects of the prevalence of technology in children's play.

One young boy interviewed summed up the attitude of some parents towards these electronic games at home. He said, 'I'm not allowed [play with games consoles]; my Mum doesn't like them'. So he plays PlayStation at a friend's house instead.

Three-quarters of the children surveyed said that there was a games console in their home. A higher degree of presence (77.3\%) was recorded in children in rural-based schools, compared to $71.1 \%$ of cases in urban schools. Children from the older age group reported a higher level of ownership, with almost $87 \%$ positive responses. Within the younger age group, nearly $62 \%$ of children said there was a games console at home. More boys (nearly 79\%) than girls (over 70\%) responded positively.

Children in School 2, a rural school in a fast-growing commuter town, reported $100 \%$ presence of a games console at home. Children in Schools 4 and 9, the two designated 'disadvantaged' urban schools, reported the second and third highest levels of having a games console at home (91.3\% and 81\% respectively). The lowest level (59\%) was reported by children in School 8, an urban multi-denominational school, followed by School 3, an urban Gaelscoil (63\%). Children in all other schools reported levels ranging between $67 \%$ and $75 \%$.

The findings for the presence of a games console in children's own rooms showed that nearly $29 \%$ of children had them. Older children were more than twice as likely (nearly $39 \%)$ to have them than younger children (18\%), while rural-based children reported a higher level (almost 31\%) of having them compared to urban-based children (almost $26 \%$ ). There was only a very slight difference between the genders: $28.2 \%$ of girls and $29.2 \%$ of boys said that there was a games console in their rooms.

Figure 8 compares the possession of a games console at home and in children's own rooms across the 10 schools surveyed.

- The highest level of having a games console in the child's room was reported by Schools 4 and 9, the two designated 'disadvantaged' urban schools, at $47.8 \%$ and $47.6 \%$ respectively — the same schools that reported the second and third highest levels of having a games console in their homes (see above).

- Children in School 8, an urban multi-denominational school, reported the lowest level of games consoles in their rooms (just over 11\%), followed by children in School 3, an urban Gaelscoil (over 13\%). 
- Possession of games consoles in the rooms of children in the remaining schools ranged from $16 \%$ to $38.5 \%$.

Figure 8: Games consoles in the home and in child's room, by school type (\%)

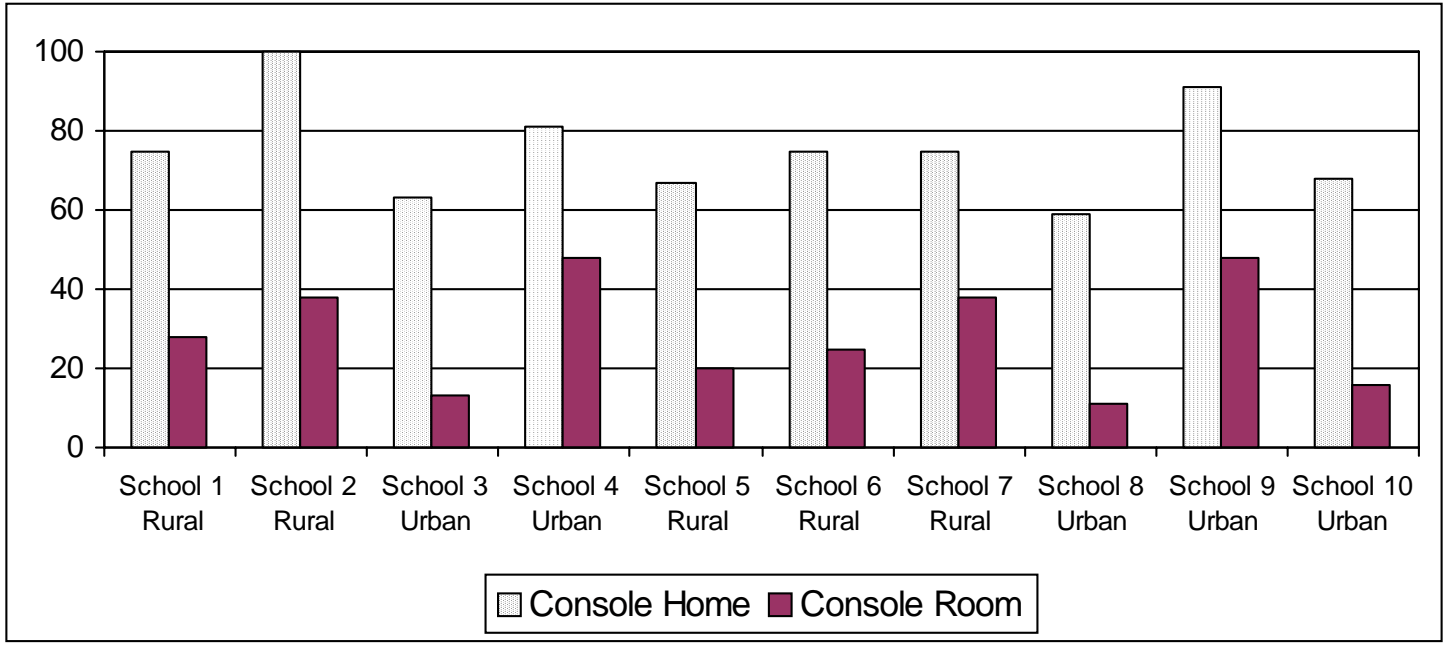

Note: See Table 1 for full description of the 10 school types.

Over $65 \%$ of children also said that there was a portable electronic game, such as a GameBoy, in their household. Nearly three-quarters (74.3\%) of the older children and over half (55.4\%) of the younger children said that they played with these game devices. Children from urban and rural schools reported almost the same level of presence of these games - $65.8 \%$ of urban children and $65.1 \%$ of rural children. Boys reported a higher level of presence of these games at home (almost 70\%) than did girls (over 60\%).

\section{Contexts for playing computer or console games}

More than $95 \%$ of children in the survey said that they play computer or console games. All of the older children, and just under $90 \%$ of the younger children, reported playing console games, with slightly more boys (98\%) than girls (92\%) saying they played. Children were also asked about the context in which they play these games: where they played (e.g. in their own room, in a family room or at a friend's house, which could also mean the home of a relative) and with whom they played (e.g. friends, siblings, parent, alone). They could select as many options as were true (see Figure 9).

Figure 9: Contexts for playing computer or console games (\%) 


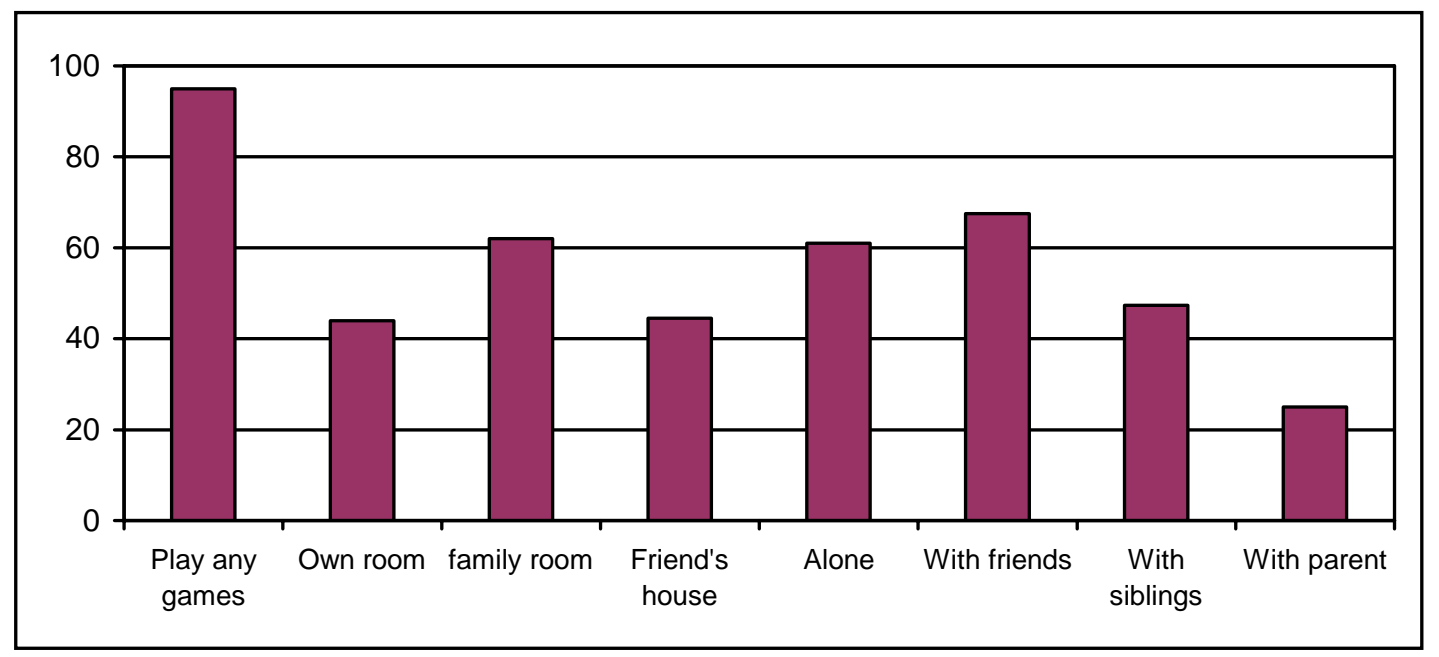

Almost $44 \%$ of children said they play computer or console games in their own rooms. Older children were twice as likely (over 59\%) to play in their own rooms than younger children (26.6\%). Girls were only slightly less likely (42.7\%) than boys (44.7\%) to play in their own rooms.

Overall, $62 \%$ of children said that they play computer or console games in a family room (in this context, this could also mean a sibling's bedroom). Boys (almost 65\%) were a little more likely than girls (nearly 59\%) to play in a family room. Younger children (over $68 \%$ ) said that they play in a family room, compared to just less than $56 \%$ of older children. Urban-based children are far more likely (over 68\%) to play these games in a family room than their rural counterparts (57\%). Less than half of all children (44.5\%) said that they play computer or console games at a friend's house (this could also mean the home of an extended family member, such as a cousin).

Over $61 \%$ of children said that they play console games alone and over half of all children said that they also played computer or console games with a friend (the responses were not mutually exclusive). Almost half (47.3\%) of all children said that they play computer or console games with a brother or sister. Younger children gave this answer slightly more frequently (48\%) than older children (46\%), as did over half of girls (almost 53\%) compared to just under $43 \%$ of boys.

The response to 'Who do you play with?' that got the least answers was playing with a parent - just under one-quarter of all children surveyed said they do this. Younger children (over 32\%) gave this answer far more frequently than older children (nearly $18 \%$ ). A wide gap is also noticed between urban and rural households, with nearly $32 \%$ of urban children playing games with a parent compared to less than $20 \%$ of rural children. Girls (nearly 24\%) were only a little less likely to play with a parent than boys (25.5\%).

\section{Internet use}

Children were asked whether they use the Internet (as opposed to it just being present in the home). About half of all the children surveyed (49.5\%) said that they did. There was a small difference in using the Internet between urban and rural children, at 52.5\% and 
$47.4 \%$ respectively. Boys (nearly 51\%) appear to use it more than girls (48\%). Internet use rises with age and older children were also more than twice as likely (over 66\%) to respond positively than younger children (30\%).

The older children in the survey were given 7 predefined options of Internet uses, plus one open option where they could describe 'other' uses (see Figure 10). The same categories were used to describe activities that younger children specified in an open question. Children could select as many of the options as were true.

Figure 10: Uses of the Internet (\%)

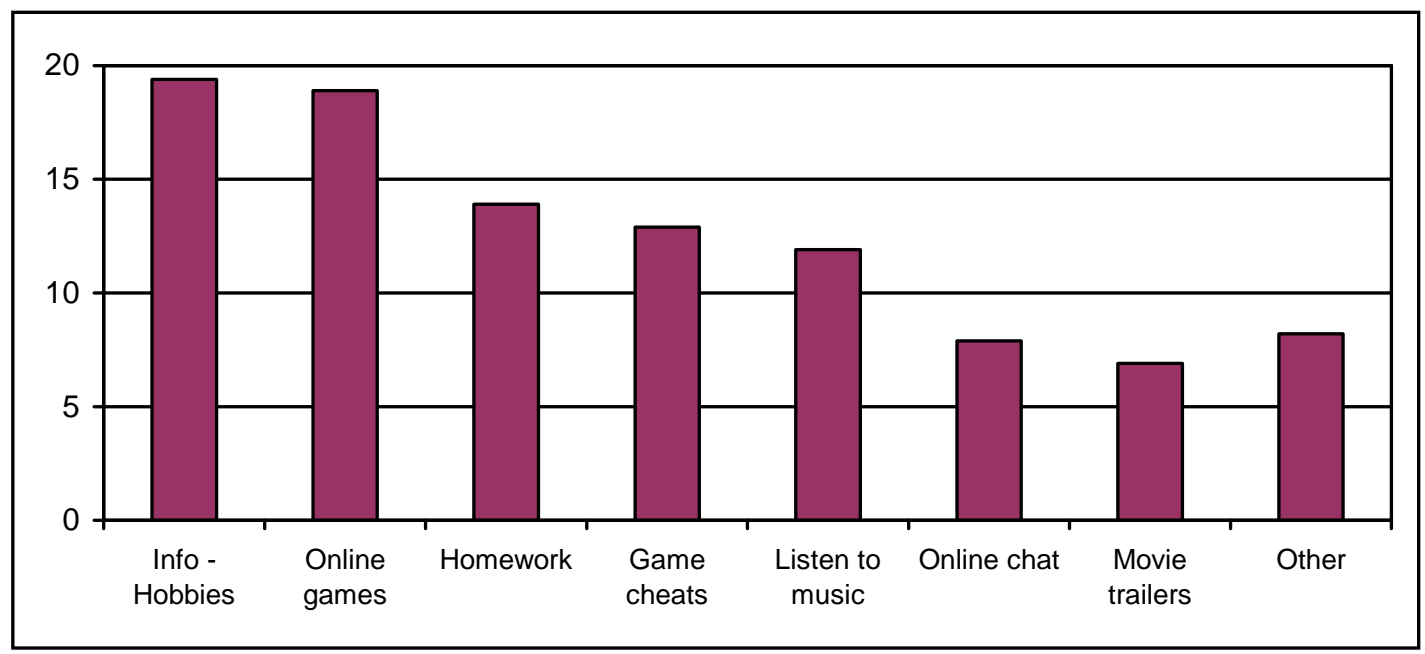

The most frequent response (over 19\%) for using the Internet was for information on hobbies and interests. Older children were nearly 12 times more likely (over 50\%) to give this answer compared to younger children (just over 4\%). Children in rural households gave this response in just under $30 \%$ of cases, compared to over $24 \%$ of city-based children. Boys (over 31\%) were more inclined to use the Internet for this purpose than girls (nearly 23\%) - as one boy who likes to research his interests online put it, 'to look up websites on Harry Potter'.

Playing online games was a close second choice, at just under 19\%. Almost 33\% of older children and nearly $20 \%$ of younger ones gave this answer (one 5-year-old girl who likes to play games online said, 'My Mammy lets me go on BBC and I play games'). A similar gap is apparent with gender - over $32.6 \%$ of boys and $20 \%$ of girls responded positively. There is a small difference between urban children (almost 26\%) and rural children (over 27\%) in this category.

Using the Internet for homework or school projects is also a popular option, at nearly $14 \%$ overall. However, older children are almost 18 times more likely (37.1\%) to give this answer compared to younger children (only 2.1\%). Children in rural homes gave this answer in $21.5 \%$ of cases, slightly more than urban children (17.4\%). Boys were slightly more likely (nearly 21\%) to use the Internet for this purpose than girls (over 18\%).

Older children, in particular boys, spoke about using the Internet to find game cheats, linking their Internet use with console game playing. Listening to music (11.9\%) was the next most frequent response: over $30 \%$ of older children gave this answer, compared to 
only 3.5\% of younger ones. At just under $8 \%$, online chat/e-mail was selected almost equally by boys (nearly $12 \%$ ) and girls (over 10\%). Watching movie trailers (nearly $7 \%$ ) was far more popular with older children (over 18\%) than with younger ones (only $1.4 \%$ ). Nearly $7 \%$ of girls gave this answer and $12.5 \%$ of boys.

\section{Mobile phone ownership}

An increasingly pervasive form of technology available to and used by children is the mobile phone. Figure 11 provides an overview of mobile phone ownership according to age, gender and urban/rural location. Almost $40 \%$ of all children surveyed, between the ages of 4 and 12, said that they had their own mobile phone. Of the younger age group (4-8 years), 18\% said that they had a mobile phone. (As one forward-planning 7-year-old said, 'I'm getting one when I'm ten'.) Over 59\% in the older age group (8-12 years) also owned a mobile phone. The level of ownership was higher among city-based children (43.3\%) than rural-based children (37.2\%). Girls were slightly more likely to have a mobile phone (over $41 \%$ ) compared to boys (38.5\%).

Children in the two designated 'disadvantaged' urban schools reported the highest levels of mobile phone ownership, at nearly $62 \%$ and $61 \%$. The lowest level of ownership was reported by children in an urban multi-denominational school (22.2\%), followed by children in an urban Gaelscoil (25\%).

Almost $14 \%$ of all the children surveyed said that they had a mobile phone with a built-in camera. By age group, almost one-fifth of the older children and just over $7 \%$ of the younger children said that they had such a phone. Camera phones were more common among urban-based children (17.5\%) than rural-based ones (11\%). By gender, 13\% of girls owned a camera phone and over $14 \%$ of boys.

Children in the two designated 'disadvantaged' urban schools reported the highest levels of camera phone ownership, at 34\% and 23\%. The lowest rate of ownership (3.6\%) was reported by children in the same urban Gaelscoil that indicated the second lowest rate of phone ownership overall. At 6.7\%, children in a rural village school (School 7) reported the second lowest rate of camera phone ownership.

One boy, who did not have a mobile phone himself but knew all about camera phones, said: 'My cousin has one. It has picture messages - they're disgusting ones!'

Figure 11: Mobile phone ownership, by age group, location and gender (\%) 


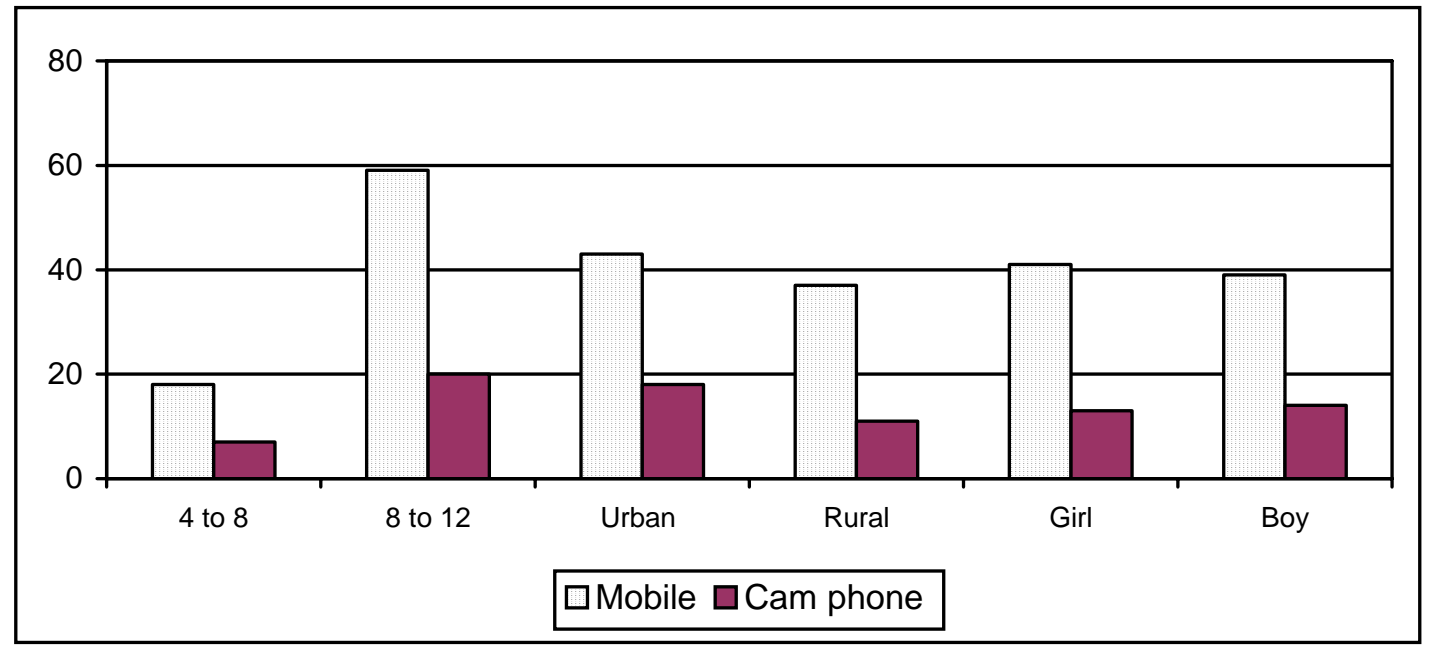

\section{Desired possessions}

Looking at the kinds of toys and possessions they would like to have (as opposed to what they currently play with), children were asked to name three gifts they would like to receive. Since the survey was conducted in the run-up to Christmas, the question was phrased to ask what they would like to get for Christmas. This was an open question and children were free to mention up to three items. Responses were classified into a number of categories, including traditional toys, sports toys, technology hardware and software (see Figure 12).

Figure 12: 'Gifts for Christmas’ (\%)

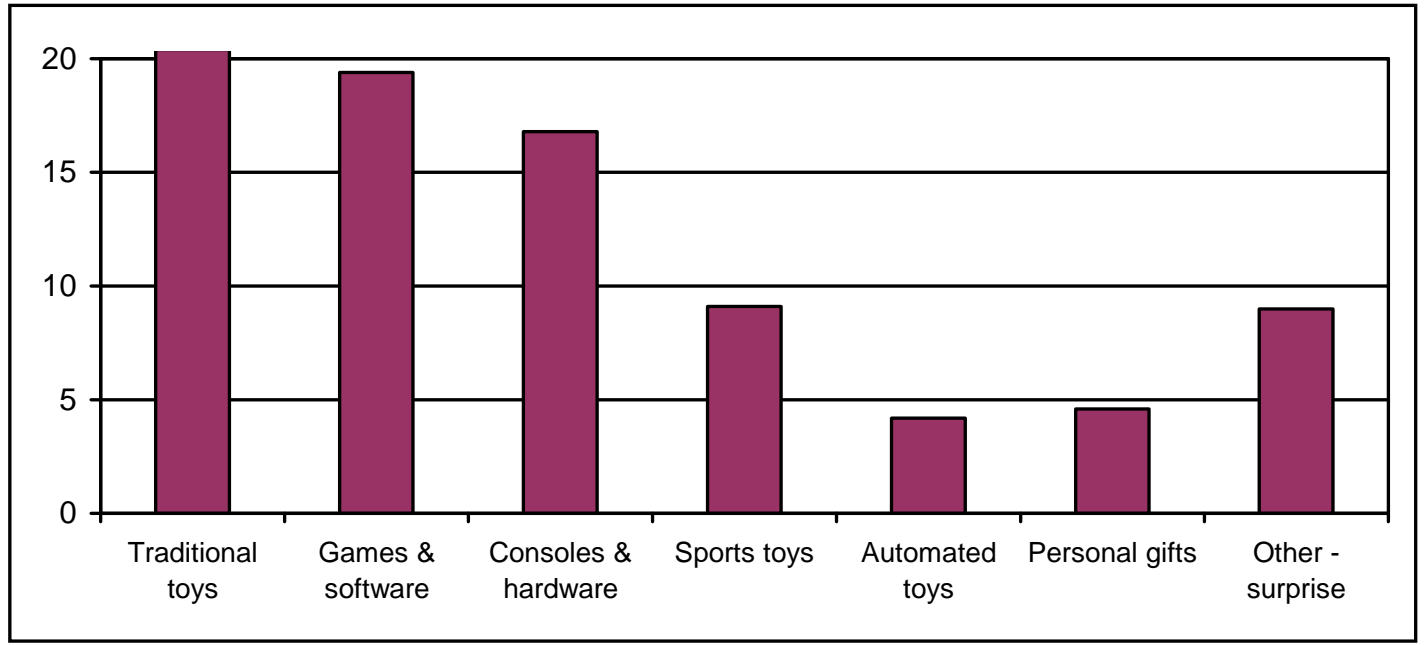

Traditional toys (including a range of toys such as tractors, dolls, figurines, books and board games) form the bulk of responses, at over $20 \%$ overall. $37 \%$ of rural children gave this answer, as did over $24 \%$ of urban children; this $13 \%$ difference reflects the higher level of interest of rural-based children in traditional toys. Slightly more girls (32.5\%) than boys (29\%) were interested in receiving traditional toys. There is a wider margin in terms of age: younger children (43.6\%) gave this response more than twice as much as 
older children (18\%), indicating that children lose interest in traditional toys as they grow older.

Sports toys (including a wide range of sports equipment, such as branded team jerseys, air hockey tables, roller blades and skateboards) were the fourth most popular choice of gift, at just over $9 \%$. Over $17 \%$ of rural children wanted sports toys, compared to over $10 \%$ of urban children, with less interest from girls (10\%) than boys (18\%). There is a smaller difference between the age groups: over 15\% of younger children and nearly $12 \%$ of older ones specifying a sports-related gift.

Personal gifts (including grooming items, such as cosmetics and hair-straighteners, as well as jewellery and non-sportswear clothing) were chosen by more urban-based children (over $8 \%$ ) than rural-based ones (5.5\%). Girls named the vast majority of these items (over $12 \%$ ), with only $1.4 \%$ of boys wanting them. Older children were also twice as likely to choose personal gifts than younger ones, $9.3 \%$ and $4.5 \%$ respectively.

The category of 'surprise' (which could be described as unspecified or 'other') was important because it occurred so frequently. Twice as many rural as urban children (13.7\% compared to 6.5\%) wanted a 'surprise' gift. At 10.3\%, slightly more boys than girls (9.9\%) gave this answer. It was also a more frequent response from younger children (over 12\%) than older ones (just under $8 \%$ ).

In terms of technology, various types of hardware and entertainment software were mentioned by children. Computer games and games titles for consoles (including PlayStation, Nintendo and XBox titles) were the second most popular choice of gift. (Games hardware, the actual games units, were mentioned frequently enough to be classified separately, including those for GameBoy.) In many instances, actual titles were used. Over $23 \%$ of rural-based children gave this answer and over $16 \%$ of urban-based ones. Three times as many boys (nearly 31\%) as girls (nearly 9\%) gave this response. Nearly $29 \%$ of older children, compared to $11 \%$ of younger ones, nominated games titles.

Various types of media hardware (including TVs, DVD and CD players, and computers) that children wanted (usually for their bedroom) were also listed. At $10.5 \%$, this is the third highest ranking of specified gifts. Nearly one-fifth of urban children (19.5\%) and $12 \%$ of rural children specified an item in this category. $19.5 \%$ of girls named a media hardware device, as did $12 \%$ of boys. The greatest contrast is between the age groups, with nearly $27 \%$ of older children giving this preference compared to only $5 \%$ of younger children. Thus, the desire for these media devices increases with age.

The hardware devices designed for games were also frequently mentioned. This category covers a range of brands, which were specified on the questionnaires. Over 6\% of children made this request. $10.6 \%$ of rural children and $8.2 \%$ of urban children named one of the major games console devices. Boys (14.4\%) were three times more likely to give this answer than girls (4.5\%). Older children also more frequently specified a games console (12\%), than did younger children (just under 7\%).

For the category of automated toys (including a range of remote control toys, robots and similar devices), rural-based children (over 8\%) were more interested in these than urbanbased children (4.5\%). Boys (nearly 10\%) gave this response three times more frequently 
than girls (2.7\%). This was also a slightly more popular answer with younger children (nearly 7\%) than with older ones (almost 6\%).

One 8-year-old girl, with a long and varied gift list, said she wanted, 'A bike, Sims, GameBoy Advance, Password Journal, Bratz stuff, surprise ...'

\section{Conclusions}

The findings on how children like to spend time with their friends suggest that, given the opportunity, children will make their own fun. Although it was beyond the scope of this survey to monitor actual time spent in different leisure activities, given the Irish climate and the fact that for reasons of supervision, safety or suitable play space children are sometimes confined to indoor activities, this belies concerns that children are inactive or over-reliant on technology for entertainment. Most of the children surveyed preferred to be active and involved with their peers.

On the other hand, technology seems to be present and available in the average Irish home. When alone, children often turn to technology for their fun and most of them have quite a high degree of access to technology. Issues of supervision were not explored in this section of the research, but emerged in discussion with parents and teachers. Age was as a major factor in the choices that children make, particularly in relation to technology. Gender seems to be less of a differentiating factor, although boys seem to be more proactive, or interested, in using the Internet. Given the responses to the question 'What I like about playing' and the level of difficulty that children had with this sentence, perhaps they have not been asked often enough what it is they value in their play or maybe they have not been encouraged to reflect on what they enjoy and why. 


\section{$4 \quad$ What children and adults say about play and technology}

One of the objectives of this study was to access the views of both children and parents on the use of technology in their leisure activities. Focus group discussions were the main source for the qualitative data from children, although some points raised in association with filling out the questionnaire are also included. The focus group sessions were designed to be less formal than the questionnaire sessions in order to facilitate broader discussion and to encourage openness. Although the discussion sometimes drifted, the main focus was on the role and impact of technology in play, rather than a general discussion of play.

Hennessy and Heary (2005) define a focus group as 'a discussion involving a small number of participants, led by a moderator, which seeks to gain an insight into the participants' experiences, attitudes and/or perceptions'. They identify the advantages of focus groups, particularly when working with children, as providing a safe familiar environment, the flexibility of the method and a way to rebalance power between children and adults.

Focus groups for this study were first conducted with the older children in the sample (aged 8-12) in each of the 10 schools, representing 2nd to 6th class. Between 6 and 8 children were invited to participate in a recorded discussion. In one school, a member of staff advised on the focus group selection. In the other schools, the 'name out of a hat' method was used. Efforts were made to ensure equal or proportional gender representation (in terms of the constituents of the survey respondents). Topics were used to guide and stimulate the focus group and to create continuity between sessions for comparative purposes. The topic content was based on the main technologies with which children interact on a regular basis for the purposes of play or leisure. In addition, efforts were made to explore the context in which technology/media is used or consumed. Children were also encouraged to raise topics themselves.

The sessions were held immediately after the questionnaire session with the older children. The focus groups were presented as a type of 'circle time', where individual children responded to a particular question or in answer to someone else's response. There was very little dialogue involved. As can be expected with this age group, there was a lot of over-talk and verbal jostling, and contributions tended to be in shorter statements rather than in more extended discussion.

On the whole, boys were more likely to dominate the discussion than girls. Younger children were quieter than their older counterparts. When addressed directly, the shy children (usually girls or very young boys) tended to almost whisper. Responses tended to be quite direct, although a few of the older children were able to articulate a higher degree of reflected responses.

\section{General findings}

In terms of children's general discussions on the theme of play, some universal trends emerged. Children tend to like outdoor activities and prefer to play with friends, but as 
they get older, their interest in outdoor pursuits wanes. Factors such as weather, time of year and the availability of playmates influence the leisure/technology choices they make.

Regardless of school, rural or urban, children seem to consume the same kinds of programs and games for the same kinds of reasons. All children use mobile phones, the Internet, games consoles and television in much the same way. Television is by far the most important of the leisure technologies and although both boys and girls play console/video games, this pursuit is more popular with boys. All children prefer to play these games against someone else. No common parental policy or rules regarding the use of TVs in bedrooms could be deduced from the discussions and equally, where rules are in place, different children reported different views in terms of compliance and subversion.

While there was some evidence of boisterous or aggressive play in children's comments, it was, in general, quite limited. In two of the schools, children described physical chasing games that involved a degree of aggression or where hurting people was part of the game. In one school, 'pranking' (nuisance phone calls or text messages) was discussed in a more serious way than in any of the other schools. However, these passing observations should not be used as a basis to infer a particularly high level of anti-social behaviour in these schools.

Throughout the focus groups, a number of central themes emerged and provide a useful framework for the presentation of the main findings.

\section{Play habits}

Although focus group discussions centred on the role of technology in leisure, many of the children also discussed their play preferences in general and revealed a wide range of play activities. Sports activities were widely popular, with soccer, football (GAA) and hurling being the main ones listed. Cycling, chasing games, basketball, gymnastics, hockey, trampoline, dancing, cheerleading, swimming and tennis were all mentioned as activities enjoyed and valued by children. Some children indicated that they were training as part of a team. A few children spoke about playing pool or fooze-ball type games.

A number of rural-based children spoke about farming activities as leisure. Playing with animals, such as a pony or dog, was mentioned, but infrequently. Traditional indoor games, such as playing with cards, charades, board games (Monopoly, Cluedo, Frustration and Don't Wake Dad!), were mentioned, with one child immediately mentioning that he liked the electronic versions: 'Board games ... but I like the new ones that are on DVD. You know, the computer versions.'

Shopping emerged as a popular leisure pursuit in the open questions on the questionnaire and was followed up in some of the focus group discussions. It was discussed at length in one school where a girl said that it was her preferred leisure pursuit. This arose in the context of a number of children describing what they liked to do during their free time, with several boys mentioning activities such as football; one girl spoke up and said that she liked to go shopping. The other girls in the group agreed with her, although the boys did not. One girl described her ideal leisure pursuits as '40\% TV and 50\% shopping'. 
Some children brought up reading as a pastime in the focus groups, if only to express their dislike. Three of the negative comments were 'I don't read at all', 'I only read in school' and 'I don't like reading'. Others, however, were more positive. Two girls, for example, were enthusiastic about their reading: 'I love Jacqueline Wilson's books' and 'I love The Worst Witch books'.

\section{Parental rules and supervision}

Children's access to technology is mediated through the adults around them. If there are limits set on the time a child can spend engaged with technology at home or at school, these boundaries tend to be placed by their primary caregivers, parent or teacher, even though the parents of children currently in primary school, and many of the teachers, grew up in an environment with fewer options for interaction with technology.

Children reported regular routines during school term, involving homework and eating dinner before being allowed to play or watch television. Some children said that what they did after school depended on factors like their mood or the weather. Some comments on after-school routines included:

'Well, I'd have my dinner, then I'd probably go do my homework and watch television. Then after, it depends if we have training or something like that.'

'Em, have my dinner, then I do my homework and then it depends on what time I finish my homework, I might go outside or else I'll watch television.'

'Dinner, homework and television, and PlayStation, and maybe go outside.'

'Dinner, homework, if I haven't got soccer training or hurling or football, television.'

There was a great variation in the application of rules about TV viewing, game playing and Internet/computer use. The most common rules that were discussed were time limitations (such as a maximum of 2 hours per day) or doing homework and having dinner before watching television. Comments included:

'I don't really have any rules on TV' (a child who controls his own TV viewing)

'I have to do my homework and then I watch TV' and 'Yeah, can't watch TV before homework' (two children agree that homework has top priority)

'No, I just do what I want.'

Adult: 'Is there anything you're not allowed watch on TV?'

'No.'

'I'm not allowed watch kinds of movies that are on late or ...'

'I'm allowed watch anything.'

Adult: 'And is there a curfew for TV? A time the TV has to be switched off?'

'Half four. Half four and then I go back at seven. My TV does be left on until two o'clock.'

Adult: 'In the morning?'

'Yeah, sometimes.'

'Only do an hour of PlayStation and two hours of TV.' 
One child mentioned not being allowed to watch programmes or films rated over-18 years, while another child described a situation based more on parental discretion: 'Well, em, I've no rules except like if it's a mature audience, my Mom has to have seen it or something. I think that would be, em, that my Mom would let me, but if it's something she hasn't seen that might be really bad, she wouldn't let me watch it.'

Bedtimes were discussed and a few of the children admitted to having a set bedtime, but said that they did not go to bed at that time. Of the focus group children who had TVs in their bedrooms, a minority said that they obeyed the curfew. Others said that either they did not have a curfew or that they disobeyed it. A pattern that was raised formally or informally in all schools by some children described waiting until their parents had gone to bed and then switching the TV back on. As one girl put it, 'My Mom sees I'm reading and says "Go to bed now" at a quarter to eleven and when they're asleep, I turn the telly on.'

Others, in both urban and rural schools, said that they were not supposed to watch TV on weekday mornings because it delayed them in getting ready for school.

Parents were asked about their views on children having TV, computers and other electronic equipment in their rooms, as opposed to in a family room. Some parents said that it can be convenient or useful, for example, when a child is ill or when the child wants to watch a different programme to another member of the household. However, $66 \%$ of parents said that they were very much against children having these devices in their bedrooms - one parent's comment was 'Anyone that allows children to have a computer online in their room should be shot'. A small number of other parents expressed reservations. Interestingly, 37\% of children surveyed said they had TVs in their rooms.

The main concern for parents was what children might be watching and the difficulty of supervising a child's viewing, as well as monitoring the time spent watching. One parent said that her children had TVs in their rooms, but only local channels (not cable, satellite or digital services); she felt that this was easier to control. Several parents said that they were 'guilty' of letting their child have a TV in their room and that they tried to be careful about the child's use of it. One parent said it was less of a concern where older children were involved, but that it was more problematic with younger ones. One parent said that he would be concerned about issues of safety if his daughter had a computer in her room.

\section{Television and film viewing}

Over $98 \%$ of the children who participated in this study had a television at home. In the schools where television was universally possessed, the children expressed surprise that not everyone had one. The absence of a television was reported as being a deliberate parental decision and one child said 'I prefer reading anyway'.

In all schools, many children said they would prefer to be outdoors, engaged in other activities (sports, farming, playing with animals), rather than watching TV. These were activities that were repeatedly mentioned, although numbers were not formally recorded. Weather and time of day were mentioned as being factors that influenced when television was viewed. Some of the children's comments about watching TV included: 
'I don't really watch TV. I prefer to play outside and I play my own games in the tree house and that. I watch the telly like if it's raining or if it gets dark' (a boy who uses TV as a last resort)

'In the winter you play video games and watch TV and all' and 'We get homework and when you're finished your homework, it's dark outside and you can't go out' (two children discuss turning to electronic entertainment)

'Just inside, I don't go outside'

'Boring!'

'You're missing out on like, telly'

(a boy interrupts a girl who says she does not play outdoors)

Most of the children participating also said they watched a good deal of TV. Although this might appear to be contradictory, seasonal after-school daylight hours/weekends, weather, appropriate leisure facilities, parental concerns/schedules - all influence the leisure options available to children at any time. $37 \%$ of children reported that they had a TV in their own bedrooms (somewhat higher than the international average), so they could opt out of family viewing. One child described a typical day: 'I do my homework, watch telly, play, watch more telly, then go to bed.'

By far the most popular TV genre watched by children was comedy. The same shows were frequently named across the range of schools. One boy explained that the widespread popularity of comedy was simply 'because they make you laugh'. Children did not discuss characters or situations in terms of clear identification with them, or in relation to their own lives. 'The Simpsons' is almost universally watched. In one school, a girl sang the programme title tune, prompting a general chorus of 'Yeah'. When two children dissented from the general view, the others reacted in surprise; the exchange was as follows.

'No? You don't like The Simpsons?'

'How can you not like The Simpsons? Everyone loves them!'

'It's weird ...'

'I don't mind them, but they wouldn't be my favourite.'

Soap operas were popular, particularly with girls. Both boys and girls spoke positively about 'Coronation Street'. Its popularity seems to be due to an unusually high level of humour within the genre: '... because it's funny!' In one school, several children agreed that they watch soap operas from 6.30pm to 8pm most evenings during the week.

Popular vote shows appeared to be widely viewed, though only a small number of children said they had actually cast votes. The most frequently named one (which was current at the time of the survey) was 'I'm a Celebrity, Get Me Out of Here'. In one school, a girl expressed frustration that most of these programmes were British or American, and that voting was too expensive and only possible for the UK broadcasts.

Interest in drama appeared to be quite low. The US forensics-based drama 'CSI Miami' was named in a number of schools. In one case, a particular TV channel was named and true-crime programmes, as well as documentaries about animals, were the more popular kinds of factual programme - 'On Discovery, I like to watch those programmes about how people die and crime and that.' 
News seems to be something that parents watch, but that children leave the room for. One child described having to give up control of the main household TV at 6pm; instead of remaining with his family, he withdraws to his own room: 'I have two televisions and I have to stop watching the big one at six because my parents watch the news and I've one in my room and I go up there and watch it.'

Children in most schools presented a similar viewing pattern: they watch some programmes, such as soap operas, with their family, but they then withdraw, to their bedrooms in some cases, for something they really want to see. This is partly due to the fact that their parents might want to watch something else or that they prefer not to be disturbed or disrupted in their viewing. One of the focus groups described the advantages of viewing TV in their own rooms as follows:

'I watch the soaps with my family.'

Adult: 'Yeah?'

'Yeah.'

'Soccer and sports on my own.'

'With no-one annoying you.'

'Yeah, they'd be walking in front of the television ...'

'And they'd be talking as well ...'

Making noise ...'

'In case she wants to watch Eastenders and I want to watch something else ...'

Sport programmes were often mentioned by boys; live football and rugby matches were particularly popular. As described above, some children felt it was better to watch sports on their own than with the family. One boy explained his TV diet as 'Soccer, rugby on television, hurling and Gaelic [football]', while a girl revealed her football favourites 'I like football and I follow Man United.'

Stunt-type shows, such as those screened by music channels like MTV, were also mentioned, more frequently by boys than girls, although both seem to watch and be aware of these programmes. 'Jackass' was named in a range of urban and rural schools and by both boys and girls - '...'cos they're freaky. You watch people scream'.

Girls were especially enthusiastic about horror or scary films. Children in a couple of schools raised this genre. Horrors were described as being funny and this word recurred in several schools. One child described her ideal night-in, watching horror movies: 'I love the winter when the fire's on and stuff and it's nice and warm and then, you know, you've rented a DVD of a scary movie, you don't even need to know what it's about because you know it's scary so you know it's gonna be fun!'

One focus group discussed a particular PG-13 rated horror film, as follows:

'The Grudge is so funny ... the naked Chinese guy...'

'Yeah [giggling]'

'But like, it's funny if you want it to be funny.'

'It's really funny, it's totally funny...'

'It's actually quite scary when she's sitting there ...'

'In the ring ...'

'Yeah, well, The Grudge, em, it was very weird the way the boy is in every single, eh, floor that she went up.'

'Yeah, it was really scary.' 
'Yeah, but what happened was ...'

'Something came up onto her and sucked her under the bed or something.'

'Oh God, no, but in The Grudge, she's looking at the video camera footage, okay? 'cos, see, yer one says, she's walking up the stairs and ...'

'No, don't spoil it for us!'

One child mentioned not liking horror, but most of the children seemed to enjoy these films and although it could be intimidating to make such an admission in a group situation, no one mentioned being too scared to watch them. No child was observed demonstrating discomfort during discussion of these films.

\section{Music}

Very few children had a large CD collection of their own. A few children said that they did not like music (e.g. 'I just think music is a waste of time'), while it was very important for others (e.g. 'I like loads of different kinds of music'). Most of those who were interested said that they tended to borrow CDs, usually from an older sibling and often from a sister. Two children who knew what it was to lend and to borrow said, 'My brother robs my CDs!' and 'I just get 'em off my sister'.

With the exception of children in one school, very few children bought CDs from their own money. Most said that their mother would buy a CD they wanted for them and a few children said that they would ask for a CD they wanted as a birthday gift. Three children who liked music said, 'I used some of my Communion money to buy [CDs]', 'Sometimes I do and sometimes my Mom pays for them' and 'Me Dad pays for loads of CDs because he likes music'.

\section{Console Game Types}

Most of the children said that they play console games. All of the children said that they had tried console games, although not everyone liked them. Almost all had PlayStations. Only a few children mentioned owning an XBox or Nintendo GameCube. Three children who rated console games highly said, '... and playing PlayStation and watching the Simpsons', 'GameBoy and PlayStation' and 'I have a PlayStation 1, a PlayStation 2, a Nintendo 64 and a Nintendo GameCube'. One boy who was enthusiastic and loyal to the console he owns said, 'The XBox is the best game - it's got the best graphics'.

Some children said that they would play every day, others not so often. Getting a new game acted as an incentive to staying in front of the console until the player gets through. Playing against other people is also reported as more attractive than playing alone. One focus group described playing a new game:

'If you have a new game you might ...'

'... and it took five hours to complete it.'

Adult: 'And did you complete it? Yeah?'

'Yeah.'

Adult: 'And did you play it all in one run or ...?'

'Yeah! I couldn't leave the run until it's done!'

'Oh ... you still have my game.' 
A few children said that playing depended on their mood: sometimes they would play console games a lot and at other times they would not play very often. 'Sometimes I play with them a lot. It just depends what kind of mood I'm in', said one girl. Another girl explained how she got to play console games, 'I don't have a PlayStation except I play at other people's houses'.

The Sims games were widely lauded, even though some of the games are rated 18s. In fact, most children had seen, if not played, games that were rated much higher than their own age. The concept behind Sims is that the player controls an environment and is responsible for all that unfolds. A successful player runs a thriving environment, whereas if the player fails, the environment declines. Unlike many other games, The Sims has a dark side.

Action and adventure games, some of which are considered violent and bloody, seem to afford the children great opportunity for fun. Children in all schools said they had access to, or even owned, an 18s-rated game that involves car theft and pimping as part of the scoring storyline. Although some borrowed games belonging to an older sibling or cousin, others said that these games were bought for them by a parent or a relative.

One boy explained the range of console games he likes as 'Racing games and adventure and fighting. Racing games are cool because I like cars mostly ... The adventure games give you a certain thrill and fighting games are just cool'. One child with an eye to the future said, 'I like being the Manager of soccer teams'. A girl who likes speed-based challenge games said, 'I like the ones that you race, any kind of ones that you race'.

Both boys and girls expressed enjoyment of these games in all locations. Some children commented on graphic quality, though not audio. One girl referred to playing on her Dancemat (a PlayStation plug-in dancing game). Two boys discussed a controversial new games release: 'There's new games, like Grand Theft Auto just came out [San Andreas]' to which the other boy replied, 'Grand Theft Auto is boring!' A girl in another school expressed another opinion: 'I like playing the PlayStation with Grand Theft Auto on it.'

Parents were asked if they bought games, CDs or films for themselves or for their child. Most reported that they did not buy, or rarely bought, for themselves; most buy or hire games or films for their children. One father said that his wife usually takes care of buying these items for the children. Two parents said that the child's father usually picks games for their children and that they did not know much about them. One parent said that he reads game reviews. Two parents who buy games for their children said, 'He tells me what he wants' and 'I'm given the name, I'd buy, and that's it!' One girl described her mother's tolerance of electronic toys: 'My Mum doesn't really approve of GameBoys, but she still lets me have them.'

Some parents commented that they do not buy these games at all, while others said that they buy what the child asks for or that the child tells them the title and they get it. One parent said that horror was out of bounds, another that she did not like games that feature car theft and another that she will not allow anything that promotes disrespect of other people. Many parents also look for educational content or languages. Other words that parents used were fun, entertainment value, suitable, playability, learning curve, graphic 
quality, parental guidelines and film characters. Most, however, look for ageappropriateness and try to avoid violence or sexual content. Violence is one of the concerns most frequently articulated. A few parents said it depended on the child and their level of maturity. Some parents said that they did not find the ratings very helpful. One parent commented that she was sure the games were classified by proper authorities, while another said that he felt they were not screened enough. Parents did not seem to be aware of who was responsible for classifying games. ${ }^{1}$

Observing children's discussions on this topic of game preference suggests that perhaps part of the fun of violent 'shoot-'em-ups' is adult disapproval and shock, or the thrill is in doing something they should not (due to age ratings). However, many children seemed to feel that the violence was not important; it was more about reaching a high score. Some children could not explain the appeal; one, when asked why he liked these 'killing games', simply answered 'Don't know'. Another child in the same school responded that he liked 'video games that are violent'; when asked why, he said, "'cos they're fun' and then went on to talk about puzzle games. In a different school, one child elaborated on his liking for violent console games: 'Well, they're not really that violent 'cos they're mostly cartoony.'

One of the attractions of these games appears to be their complexity and the problemsolving challenge presented to the player. As one boy said, 'I like to play shooting games ... it's not really about the shooting. It's more complex than most games. You go around and you mostly do missions. And there's like free role modes where you can just go around the place doing what you want'. Several peers agreed with this boy's explanation of the appeal of 'shoot-'em-up' games. Another child indicated that games portraying the darker side of life are more realistic and that 'you can do things you can't do in real life'.

In one of the focus groups, two children continued the discussion into how they saw themselves still playing as adults; when they were earning money and going to nightclubs, games would still be a part of their lifestyle.

\section{Mobile phones}

A high proportion of the children in the focus groups said they had a mobile phone. 59\% of children in the older age group (8-12 years) said they owned a mobile phone. One boy specified that he had had a phone since he was 9 years old. Of those who did not already own one, most wanted one. Some children said they would ask for one for a special occasion, such as a birthday, Christmas or Confirmation. One boy stated, 'I'm getting one for Christmas! A GX10'. One girl, however, said that she thought she would not be allowed get one until she was 18 since her parents did not approve.

Camera phones were also seen as highly desirable, although one child described giving her camera phone to her mother because her father did not like her having that phone.

Texting is by far the most popular and prevalent use of the phone. Usually, this involves simply keeping in touch with friends (to gossip, discuss homework and the like), letting

\footnotetext{
${ }^{1}$ While the Irish Film Censor's Office is responsible for rating cinema film releases, DVDs and videos, games are rated on a voluntary basis by the games distributors, who are members of the European Leisure Software Providers Association (ELSPA). Distributors recommend that 15s- and 18s-rated games be submitted to the local film censor. However, there is no legislation to compel this.
} 
friends know that you were on the way over to visit, or to contact a parent to arrange collection from a friend's home. One child said he used his mobile phone for various things - 'It depends. Sometimes I just keep on texting everyone and I spend about €5.'

Most of the children had credit-based phones (only one child specified that he had a bill phone). Parents, especially mothers, were the ones who paid for phone credit (i.e. it did not come out of pocket money). Some children estimated that they could spend between $€ 5$ and $€ 10$ a week in credit. Some children had the phones in case of emergency only.

'Pranking' was mentioned as a popular activity. This was described as sending silly text messages or, more often, phoning numbers to make what are known as nuisance calls. For most children, this was considered harmless fun or as a means of wasting credit. One girl said that she would dial a number similar to her own, just changing one digit. In one school, although described as a means of fun, there were slightly more serious undertones. The activities described involved ordering pizzas or making nuisance phone calls to businesses. One boy said that he only used freephone numbers and another that he called phone numbers given in advertisements. Two boys described how they got out of trouble for pranking: 'When I was pranking, someone called the Guards on me ... I took out my SIM card and got a new one the next week', to which the other boy replied 'That's why I bust my phone'.

Quite a few children said that they played the games that are installed on mobile phones. One child referred to 'borrowing' his mother's phone on more or less a permanent basis to text and play games. Only one child described using her phone to go on to the Internet to download ringtones. Downloading ringtones and games was bemoaned as a waste of credit. Although most had done it, it was considered expensive; some of the comments were 'too dear', 'a waste of time' and 'you pay about $€ 6$ - they take it from your credit'.

\section{Internet use}

Many children reported that they had access to and used the Internet. A wide range of activities was involved and a capacity to source the information desired was evident. The most frequently described activities were to listen to music (rather than download it), to check out websites of interest (e.g. bands or sports organisations, such as the GAA) and to look up game cheats. One boy, describing the information he seeks online, said 'I use it for new cars coming out, games and TV'.

Another use of the Internet is to research projects at school. One of the suggestions here was that if a project was unfinished, printing straight out from a website was a quick and simple means of completing the assignment - 'If you've a couple of pages left in a project, you can print it straight out'. This particular use of the Internet raises a number of issues. The children did not specify whether they credited the work or if they were simply taking, at best, a shortcut. The quote above implies that there was a perception that this was a simple solution to achieving a homework goal. Children also appeared to be unaware of ethical considerations, such as copying the content of a website (especially if presenting it as the child's own work), or the wider context of piracy of music and/or films through downloading via file-sharing networks. 
In one school, the children said that they all had their own e-mail address, which they could access from anywhere (these had been set up through the school). The children were very aware of security issues. They understood and spoke about the risk of viruses and taking care with e-mail. One girl discussed protecting her identity on-line - 'My friends would know who I was, but no-one else would know who I was.' A group discussion about Internet security went like this:

'Never, ever, ever give your real name or age.'

'And you have to be careful with the e-mail, and e-mails you don't know.' 'You can get viruses.'

'Viruses, yeah.'

Although some children discussed chat rooms, none said that they used them regularly. Several said that they would not use real names or contact details online. The children who spoke on this topic seemed to be reasonably aware of the issues of safety and security online. Two children in the same group talked about not giving personal information online: 'My Dad told me don't fill in your address or anything like that on the Internet', to which the other child replied, 'Yeah, 'cos you don't know who has access to it'.

\section{Children as technology experts}

The children in this study did not seem to be intimidated by or afraid of any technology. They said that at home they were often the person who would set up the DVD or programme the VCR. Even if their parents knew how to do it, the children would often 'end up' doing it anyway. They did not seem to mind coaching an adult or showing them how to use some new device, as some of the comments show: 'I taught my babysitter how to text' and 'I gave my Mam a camera phone I had because my Dad didn't really like me having it, so I gave it to her and I showed her how to use it'. Other children talked about teaching a parent how to do something on the computer or how to work the PlayStation (Dad was specified in the last case).

This contention was supported by parents themselves. Rating their own expertise in terms of information and communication technologies on a scale from 1 (novice) to 5 (expert), parents reported a reasonably moderate or high rate of expertise with most technologies. Most parents scored themselves between 2 and 5 in terms of television, video, DVD, computer and Internet. One parent noted that the family used the PlayStation 2 to play DVDs. Most said that they were familiar with mobile phones, although many rated themselves lower in terms of texting, downloads, games and handling photographs.

One area where there was little parental expertise or interest was in console games. In this category:

- 18 parents said that they had low or novice-level knowledge about these devices (one even said that he merited a below zero score);

- 7 parents said they knew a little (a rating of 2);

- 3 parents put themselves in the middle of the 5-point scale;

- $\quad$ only 2 said they had a good knowledge (a rating of 4);

- one parent claimed expert knowledge (a rating of 5) — and he described himself as 'addicted' to console games. 
In terms of 'other' technologies, digital cameras were named most commonly by the children (more stills than video), as well as MP3 players and iPods.

\section{What parents and teachers say about play}

When asked to describe how their children spent their leisure time, most parents said that their children were quite active. Many parents listed sporting activities (some teams, some informal); others named after-school classes, such as music and dance lessons. Only a few parents mentioned TV or computer/console games at this point, one relating these activities to weather conditions.

When asked to compare their own childhood experiences to those of their children, one parent replied, 'Bored wasn't in our vocabulary!' Most parents said that they used to spend far more time outdoors than their children do. One parent said that today, parents are more 'hands on'. Several people said that children used to have more freedom than today's children, where there are more restrictions, partly because parents are more safety-conscious. Only one parent said that she did not see much difference in the lifestyle - she had taken after-school classes also, but she possibly read more. One father said that there were far fewer children around for his child to play with.

Commenting on the lack of interest today in traditional toys, one parent lamented 'it's all PlayStation now'.

Most parents expressed a preference for their children to be playing outdoors, but can also see how attractive technology is to them by contrast. Issues of exercise, fresh air, interaction with friends, building skills and trying to inculcate a sense of balance and control emerged strongly from parental comments.

Parents reported that their children have many more possessions (toys as well as entertainment devices) than they had when young and observed that if people did not have something, they would made fun where they could - for example, one parent described using an old car tyre hung from a tree as a swing. Parents pointed out that consoles and home computers were not invented when they were children, naming PlayStation in particular as a popular form of entertainment with their children. One of the main concerns to emerge was that parents felt their children were less imaginative than they themselves had been, although some parents did comment that children seem more confident and advanced for their age nowadays.

When asked where they source information about games, phones and computers, no single authoritative or trusted source was identified. Most people named a range of options, such as shops, catalogues, TV, the Internet, newspapers or going into the shop and looking at the boxes. One of the other sources is word-of-mouth — from their own children or from friends. There was no reference to the Government-appointed Internet Advisory Board, which has formal responsibility for issues of child protection in relation to Internet use.

\section{Parents' views on children's use of technology}


On the role technology plays in children's leisure, all parents responded that technology had a big part to play, with some parents describing it as 'huge'. A few parents made the point that weather can be a factor in increasing indoor play and that technology is a natural fallback.

Most parents said they could see both the advantages and disadvantages of technology in play. Some parents commented on the need to be involved and that using technology for entertainment needs to be monitored, with parents aware of what their children are being exposed to. Some said that parents should guide their children and not use technology for 'childcare'. One parent observed that technology should be integrated into life as a tool: 'If the children are educated and steered in the right ways, once the resources are there to be utilised and they are in the right way, it's a valuable asset. Otherwise, it's the babysitter.'

Moderation and a sense of perspective was stressed by several parents, with a balanced, controlled, 'small doses' approach to technology recognised as good for children. They were well aware of the pressure from children to buy games consoles: 'To expect children not to play with computers or PlayStations is a bit unrealistic' and 'They all want PlayStations now because everyone has them'.

Some parents felt it important for children 'to get into technology at a young age' because it will be a part of their adult world and their childhood experiences will help to prepare them. Several parents argued that technology in play helps children to develop new skills and pointed to the range of educational programs available and how they can help with a child's developing knowledge. One parent said she thought it fed into children's imaginations.

Not all views about technology were positive. Some parents felt that technology plays 'too big a part' in children's leisure and can 'take over'. One parent reported how her son would become aggressive if he was frustrated by a game when he could not get through to the next level of play. Peer pressure was noted as a concern by many parents - cases where a child who did not have what others had is not considered cool or trendy. A few parents were concerned that interaction with friends could be diminished and that technology might be used as a substitute for friends or physical activity. Some parents fear technology makes children lazy or over-reliant on technology for entertainment. One parent even wondered how a child who was used to technology would cope without it: 'Some kids might get lost if they're used to technology and then don't have it.'

When parents were asked how they thought technology had influenced children's play, it was seen as a major influence. Parents reported that they were worried about their children's lack of activity, becoming too sedentary and being indoors too much. The word 'battle' was used repeatedly in terms of getting children to play outside and yet many parents too have reasons for not encouraging unsupervised outdoor play. As one parent said, 'Parents are more safety-conscious now about letting their children out to play'.

Several parents referred to traditional games not being played anymore (e.g. 'Cops and Robbers') and one said that technology had taken a lot of the fun out of play. There is a fear that children turn to technology for entertainment rather than to reading or to being imaginative. Others also mentioned that they observed children were less able to go out 
and create their own games. By contrast, one mother told a story of how her 5-year-old daughter, in playing pretend games with her friends, tends towards very dramatic storylines: whatever game they play includes a funeral and 'Someone always has to die!'

Parents recognised the need to take control of their children's use of technology and most saw positive effects when used in moderation. Several parents said that their sons compared to their daughters were less able to manage their time or resist technology 'It's not a good thing with boys especially'.

The issue of screen violence influencing children's play was raised by a number of parents. One reported that his daughter was quite mature for her age and could differentiate between the fantasy and reality, while another expressed the concern that some children might be more prone to influence than others and that violence could manifest itself in the playground. On the other hand, one parent said he thought children were too resilient to be influenced by technology.

Although parents had concerns about the influence of technology on play, most expressed a positive attitude overall. Most acknowledged that there were benefits as well as downsides. Several returned to the parent's responsibility to ensure balanced access to technology for their child. While there were concerns about sedentary lifestyles and the lack of creative play, there was a welcome for the skills and knowledge that technology can bring. Where peer pressure was an issue, this was somewhat countered by socialisation opportunities that can develop. One parent, commenting on the 'swings and roundabouts' nature of change, said, 'Technology has probably opened up areas and closed down others'.

\section{Teachers' views on children's use of technology}

Teachers reported a high level of access to technology at school, for both children and staff. In all cases, child computer use in school settings is highly supervised, especially when the Internet is being accessed. One school specified that they also had computer software to provide an additional level of access control for Internet use. Some teachers said that children in their locality tended to play outdoors a lot or to be involved in various clubs and after-school activities, with TV dominating the less active leisure time. Many others said that there was either more of a mix, or that more children were very sedentary, citing TV, computers and console games as popular pastimes.

All teachers surveyed said that the children had a very high level of ownership of technology. One teacher described this as 'very good'. Most teachers said that $75 \%$ upwards of homes had computers and that many children, boys in particular, had games consoles. One teacher, commenting on the high level of technology in the home, said, 'A lot of the children have access to/ownership of these devices and probably spend too much time at them'.

In relation to mobile phone ownership, teachers noted that the demand for phones seemed to reach younger and younger children each year, with some children asking for mobile phones as presents for their First Communion. Teachers seemed particularly concerned about phone ownership, 'which they probably shouldn't have in primary school'. One teacher referred to past problems with bullying by mobile phone. 
Teachers were also asked their views on children having TVs, computers and other electronic devices in their own rooms as opposed to in a family room. The majority of respondents reacted strongly against this, saying it was 'an absolute no' or that they were 'totally opposed' to technology in children's bedrooms. One teacher explained that it contributed to children being tired at school, while another said it affected children's ability to concentrate in class - 'I feel it contributes to attention deficit in class and short attention span'.

On the impact of technology on children's leisure, most teachers described technology as playing a 'central', 'huge' or 'significant' role, and something of a mixed blessing. The educational benefit of technology, particularly in terms of structured assignments, was noted by a number teachers. This was also considered to be even more positive when adults engage with or guide the child. One teacher said that it was only beneficial when supervised by parents. Teachers also commented on children's responses to using technology for entertainment and information: 'They expect the same kind of entertainment from teachers' and 'It's useful as a tool, but just as a tool'.

Some teachers expressed concern that children were becoming too sedentary and lazy, mentally and physically. One teacher described technology as 'a social retardant' and another said that it makes children insular. Some teachers feared that children spend too much time in front of a screen. One teacher, expressing a need for balanced consumption of technology and media, said, 'It can be very positive and can be overdone. There is definitely a place for it in children's lives'.

Many teachers also believed that language development and social skills have been curbed through the increased presence of technologies. One said that children seem to find it harder to communicate, especially when they are beginning to construct sentences and stories. Another lamented the loss of playground games and rhymes as the influence of TV and media has become stronger.

Some teachers thought that technology and media serve business interests primarily. They expressed concern about the powerful influence of advertising and its inappropriate content, with specific fears that small children were being sexualised. One teacher described how all the children have soccer moves that they see on TV and how hairstyles and dress style have been clearly influenced by TV.

On the whole, teachers had reasonably moderate or high rates of self-reported expertise with most technologies. Many teachers scored themselves between 2 and 5 in terms of TV, video, DVD, computer and Internet. In terms of console games, two teachers rated themselves as a 4 and one as a 3 . The remaining 7 teachers described themselves as 'novice'. Most teachers used the same kinds of technology for their own leisure as did parents: TV, DVD, video, computer, mobile phone and the Internet. One teacher said he also used a digital camera.

\section{Conclusions}

Technology is an integral part of most children's lives and a medium through which they access entertainment and within which they play. Most of the children in the study 
enjoyed light entertainment programmes on TV, with a few progressing towards factual reports and documentaries. When pressed to explain why they liked a particular genre of programme or game, answers tended to be general and only a few were readily able to articulate a thought-through response. Few of the children expressed particular interest in music, although most knew what they liked and did not like. Overall, girls seemed to be more actively interested in music than boys.

Adult concerns about exposure to violence in video, computer or console games were not expressed by the children. They seemed not to focus on the subtext of the storylines in these games; the achievement of reaching a high score and overcoming adversaries was their primary concern. While there is much debate about exposure to such stimuli having potential long-term desensitising effects or influence, there was no evidence on this topic from the present study.

Teachers share much of the ambivalence and many of the concerns that worry parents in matters relating to technology in children's play. Concerns about child safety, exposure to appropriate (or inappropriate) content, diminished creativity, lack of physical activity all these are countered by the potential learning opportunities available and the acquiring of new skills. Teachers reported specific additional concerns, such as attention deficit, difficulty with communication and impact on socialisation. However, both parents and teachers understand that technology is an important part of children's lives and that it is a long-term element, not a passing fashion. Moderated consumption appears to be the favoured method of dealing with technology in children's lives. While both sets of adults can relate to children about most technologies, the one area where adults fail to understand the appeal of a particular technology is console games.

Most children seem aware of the potential risks in the online world. They seem capable of taking the measures necessary to protect their online identity and safeguarding against external malignancy. They are not panicked by potential dangers. They also seem wise to how business tries to make money in terms of mobile phone services: they know where they are spending money when they order a download. 


\section{Conclusions and Recommendations}

While the sample used for this study is not a nationally representative one, the research findings offer an indication of trends and a number of emerging research issues in relation to technology and children in Ireland. When set in the context of larger international studies, many of the findings confirm trends towards the growing presence of technology in childhood at all ages. Particular foci of national significance are also highlighted and summarised below.

The emerging picture from the Play and Technology Survey, conducted in 2004, is that entertainment, as well as information and communication technologies, are omnipresent in Irish children's lives, mirroring international trends toward a high presence of technologies in people's homes in the developed world. Despite this, children's expressed first preference is always to play outdoors with their friends, with technology-based play a second choice. There is a definite 'bedroom culture' phenomenon among a sizeable minority of Irish children and the older a child gets, the more likely it is that he or she will engage with it. Children are very confident about using technology, again a trend that increases with age. They are also aware about self-protection online and appear to have absorbed the messages about the potential dangers of online activity. Children view screen-based violence or horror through a different lens to most adults and are not concerned about its potential effects.

\section{Family background}

Siblings provide many opportunities for play, as well as for learning about technology in play. Over $91 \%$ of the children in the survey grew up with at least one brother or sister. For $61 \%$ of these (a child in the middle or the youngest), there was an older sibling to offer some degree of influence, although there are examples of younger children influencing their elder siblings. Less than $9 \%$ of the children surveyed were only children (i.e. had no brothers or sisters). At the least, a child with a sibling is more likely to have greater choice about joint play opportunities.

One child in the focus groups referred to an elder sister working out how to use new pieces of technology in the home and learning from that sibling. Other children also mentioned borrowing music CDs from an elder sibling, usually sisters, and some referred to having access to computer/video games through older siblings. Within the focus groups, there was some minor discussion about the effect a younger sibling can have on the gaming experience: one child talked about a baby sister or brother 'messing up' a game by walking in front of the screen or interfering with the console or television.

\section{Playing with friends}

Given the choice, most children prefer to be with their friends and active outdoors. This is popular with both urban and rural children. Ball games and chasing games were the top two choices for both, with console games in third position. Younger children followed the same pattern, although older children rated console games in the middle. With girls, 
chasing was more popular than ball games, with talking in third position. With age, interest seems to wane in outdoor pursuits, with TV and console games gaining importance. This seems to be true for both urban and rural children, as well as in terms of gender. Console games are a particular favourite social activity with older boys.

Communication with friends seems to be particularly important for girls, again becoming more so with age. Both talking and texting rate highly, with the latter being a little more popular with rural-based girls than city-based ones, perhaps reflecting the level of opportunity to meet up outside of school, whereas city girls tend to favour talking slightly more than rural ones.

That shopping is named as a social activity at all is perhaps a reflection of an increasingly consumer-oriented culture. Listed by $1.6 \%$ of children in the survey, shopping as a group activity was also female-dominated and, again, seemed to rise with age. Although urbanbased children have greater access, rural-based children rated this slightly more highly (more than half of the shopping responses came from rural children; just over one-fifth of these responses were from boys and over $85 \%$ were from the older age group of 8-12 year-olds). Perhaps the added dimension of an outing contributed to the excitement for children in rural areas. This activity was named in the questionnaires, but was not often discussed in the focus groups. However, in one group, when one girl raised it, the other girls tended to agree. In only one school did most of the focus group say that they tended to buy their own CDs; in other schools, the buyers were in the minority and borrowers in the majority.

\section{Solo activities}

If playing alone, urban children are far less likely to play outside than rural children. This may reflect concerns about safety (one boy said specifically that his mother did not like him to play outside of their flat; she did not want him in the stairwells or in the square of their block). It could also reflect fewer appropriate facilities for playing outdoors in cities. Although they were lower-ranked preferences overall, rural children gave a much higher rate of response for outdoor games and cycling than urban children.

When they are on their own, all children are more likely to turn to technology-based entertainment. For urban children, the top three responses were TV, console games and reading. For rural children, they were console games, TV and playing with toys. Girls chose TV most frequently, with console games and reading at the same percentage. Boys chose console games, TV and outdoor games most often. As with the general trend towards screen-based entertainment, the interest level seems to rise with age: younger children most frequently answered that they played with toys, watched TV and played console games, whereas older children said they played console games, watched TV and read. The increase in reading can be expected due to age and development. It may also be due to the 'Harry Potter' effect (the series of books first published in 1997 that caught children's imaginations and spurred huge book sales, as well as spin-off films and merchandising), mentioned by a number of children in the context of checking out a website for interest or a hobby. 


\section{Domestic access to technology}

Although a higher proportion of older children named reading as a favourite pastime, over one-fifth said that they did not have any books in their own room. Some rural-based children cited music as a favourite pastime and also gave music as a frequent response in terms of using the Internet. Although none of the urban-based children gave music as a response for favourite pastimes, they were more likely to have a radio in their bedrooms than rural-based children. Girls had more radios in their rooms; on the other hand, boys had a higher level of ownership of CD players in their rooms. It seems unlikely that children use radios for news or information, since within the focus groups children seemed indifferent or uninterested in current affairs (they regarded it as a matter for adults or an impediment to watching what they wanted to). Tape recorders were less common in households with younger children, although this could be seen as an indication that the technology is becoming obsolete.

While 66\% of parents surveyed said they were against technology in the bedroom, with another $10 \%$ saying that they had some reservations particularly with regard to age, over $31 \%$ of younger children and over $42 \%$ of older ones said they had a TV in their bedrooms, with over one-fifth of older children and about $9 \%$ of younger ones having computers in their bedrooms. Only $16 \%$ of the survey population did not have a computer in the home. There is a slightly higher rate of ownership in rural areas, which may be partly explained by parents' concern that their children do not 'miss out' on educational opportunities or suffer isolation or deprivation by not living near a city. In the parent survey, several mentioned the importance of children gaining familiarity with technology at a young age and being equipped with technical skills for the adult world. Others mentioned some educational benefits of technology, while the majority expressed some mixed feelings about the role of technology in their children's lives.

Neither parents nor children were asked their primary reason for having a computer and Internet access at home, and some parents possibly work from home. The presence of a computer/Internet in the home does not necessarily mean that the children are allowed to use it, or even want to. The lowest levels of ownership of a home computer and Internet access were both reported by children in designated 'disadvantaged' urban schools. The highest levels were reported by children in private and Irish-language schools. When it came to possession of these facilities in the child's own room, these positions were quite different, although not completely reversed.

However, over $58 \%$ of children said that there was an Internet facility in their home, well above the national average of $30 \%$ for home-based Internet access. This was slightly higher in households with girls. Only 4\% of children said there was Internet access in their own rooms, with the differences in age, gender and urban/rural location being very small.

Just under $50 \%$ of children said that they used the Internet, although the frequency of response rose with age. Little difference was recorded in terms of gender or urban/rural location. Perhaps as their interests broaden and their confidence grows, children begin to use the Internet for a wider range of tasks. Younger children listed playing games online far more often than any other task, with online chat and games and information on hobbies lagging behind. Older children most frequently responded that they seek information on hobbies, with homework, game cheats and online games as the next most 
popular options. The most frequent options listed by girls were information on hobbies, online games, homework and music. The most frequent options listed by boys were online games, information on hobbies, game cheats and homework. This reflects a different set of priorities and interests. Where urban children listed online games, information on hobbies, homework and game cheats, rural children differed little, listing information on hobbies, online games, homework and music (game cheats was the next item). That homework creeps into the top three for rural children could reflect a lack of access to information sources, such as public libraries, rather than a greater commitment to education.

Online games can mean a range of game types, from activities on special 'channels' such as Cbeebies (the BBC's channel for young children, pronounced see-bee-bees) to Disneybranded sites, Kinder-egg games (the child gets a code in the egg) to the networked 'shoot-'em-up' such as 'Doom' (players can interact with avatars controlled by another person at any location in real time).

Overall, less than half of the children said that there was an electronic musical instrument at home. The main difference was between urban and rural households, with more than half of rural children responding positively. As stated above, urban children did not list music as a favourite pastime, whereas a small proportion of rural children did.

Nearly $60 \%$ of older children and almost one-fifth of younger ones said that they already have a mobile phone. Popular with both genders, $14 \%$ of children said they had camera phones. Children in the city were more likely to own a mobile phone than rural children, although children in all schools said that if they did not already have one, they would like one. As might be anticipated, ownership of mobile phones increases with age.

While boys gave console games a higher priority than girls, these were immensely popular with both groups according to the survey questionnaires. Possession of a console in the bedroom increases with age and is slightly more likely with boys. Boys were also more likely than girls to own a GameBoy or other pocket game.

While older children were more likely to play console games in their own rooms and younger children in a family room, younger children were more likely to play alone. Urban children were also more likely to play alone. Girls of all ages were more inclined than boys to play either with their friends or with a sibling than alone; they seem to treat games more as a social activity. Children in rural locations said that they played in their own rooms and at friends' houses more frequently than urban children did. This may reflect differences in household structure or socialising patterns.

At less than a quarter, the most infrequent companion with whom to play console games was a parent. Parents play more with their younger children than they do with their older ones and more frequently with sons than with daughters. Rural children were also less likely to play with their parents (less than one-fifth) than urban children (one-third). (Note that frequency is used here in terms of children's responses, not as a count of times.) Whether this reflects an increasing lack of willingness as a child grows, reluctance on the child's part or reluctance or inability on the parent's is not clear. However, in rating their own ability in terms of console games, $75 \%$ of parents were at the lowest level. 
The desire for entertainment hardware (TVs, stereos, games consoles, pocket games, DVD players, phones, etc.) increases with age. Although girls were less focused on games consoles, they listed more hardware choices than boys in terms of gifts they would like to receive. They also listed personal items (such as watches, hair-straighteners, cosmetics) more frequently than boys, who listed more games titles.

\section{Adult concerns}

Parents clearly feel a huge level of responsibility for ensuring that their children's play is balanced in terms of the range of activities, as well as a need to monitor and supervise what they are watching or playing. Although many parents said their children were fairly active when describing how they spend their leisure time, some parents still expressed concerns about children's use of technology-based entertainment.

Both parents and teachers voiced concern about the prevalence of technology in children's leisure, although technology use and media interests appear to increase with age in any case. Teachers, as well as some parents, voiced concern about children's imaginations being affected, fearing that their creative play could be suffering. Several teachers mentioned developmental delays (such as language acquisition), attributed to screen entertainment, that they thought affected children's socialisation. As a counterargument, at least one parent said technology had enabled her son to socialise where he had previously been unsuccessful. Both sets of adults, however, saw some educational potential in technology. Parents, in particular, were anxious that their children acquire the skills necessary to operate in a technological world.

While the majority of parents and teachers expressed the opinion that technology, particularly TV, in a child's room could be problematic, the rationale used differed. Parents were concerned about their ability to monitor the content or type of a child's viewing, whereas teachers spoke about tiredness, inability to concentrate at school and expectations of entertainment being carried into the classroom.

The technology most adults criticised, particularly parents, was games consoles. Some concerns that they might have with Internet use, or TV, could also be directed at games — that children might be exposed to inappropriate content. On the other hand, several parents said that they let their children choose the games themselves and others said that they either did not use, or find useful, the ratings system for games.

Although many children opt for sports-based games, violent games ('I like the ones where blood splatters on the screen ...', one child said in a focus group) are seen to be fun by children and abhorred by adults. Children seem to emphasise the scoring aspect or overcoming obstacles and opponents. Two or three children explained in the focus groups that the game was not really about the shooting, that the violence was not real. Others did not articulate their response beyond the 'fun' aspect. A similar low level of reflection was evident in other discussions - most children could not explain why they liked something, a factor possibly due to their age and stage of development.

Although most parents and teachers were very or moderately familiar with most technologies, the vast majority (75\% parents and 70\% teachers) rated themselves as knowing little or nothing about games consoles. Some even expressed more negative 
attitudes towards this genre - that they were not interested in knowing more - without having tried to play. Over 95\% of children said they played this kind of game. This indicates grounds for conflict: children feel that these games are an important feature of their leisure and parents tend not to know very much about what their children rate so highly. If adults fail to understand the appeal of these games for children, what can be done to bridge this gap? Children demonstrated a reasonably mature attitude to Internet use and were aware of the measures they should take for safety online. Without further research, it is difficult to assess the extent to which they can judge the impact of content for themselves.

\section{The digital divide?}

An issue of much public discussion and concern is the notion of a digital divide - that children from less well-off households may not have access to technology to the same degree as children living in better economic circumstances. Yet, the highest levels of ownership of technological possessions listed in the questionnaire, particularly in regard to the presence of technology in the child's own room, were almost always with children from the designated 'disadvantaged' urban schools. There were two exceptions to this: the presence of computers in the home and the presence of the Internet at home. In both instances, these were recorded in the designated 'disadvantaged' urban schools as being lower than in most other schools. However, in terms of the presence of these technologies in children's rooms, children from these two 'disadvantaged' schools indicated the highest and fourth highest levels of computers and the highest and fifth highest level of Internet usage.

The extent to which this study reflects the national landscape requires further research. A child in one of these designated 'disadvantaged' urban schools also produced an advanced phone during the focus group - an N-Gage (designed for wireless gaming) — the only one observed in any school.

The issue of access to computers in schools was one that varied across the sample. Three of the participating schools had computers in a more formal, lab-like setting. While the research team did not have access to all classrooms, in most schools at least one member of the research team had access to classrooms for a brief period. In most instances, a single computer was observed; usually at the back of the classroom (i.e. there is a computer in most classrooms). Often, these appeared to be older models, running on earlier versions of programs. (In the semi-structured interview, a teacher from one school made reference to the age of some computers installed in her school and said that there were only one or two computers per classroom, 'some very old', and that they did not have a dedicated computer room.) However, this element was not formally surveyed and none of the teachers interviewed said that they considered provision to be inadequate. All computer use by children at school is supervised; in one of the focus groups, one child mentioned that her father is always present when someone goes online at home.

\section{Limitations on comparisons}

With only very limited comparative data from 10 or 20 years ago, it is difficult to chart how children's lives are changing in terms of leisure. This is the first study of its kind in 
the Irish context. However, it is generally accepted that Ireland has experienced great societal change, with increased migration, the return of emigrants and the upturn in the economy (CSO, 2003). The range of schools participating in this research was broadly representative of the educational options available to children in Ireland. In several schools during the questionnaire session, children referred to a variety of family arrangements (e.g. step- and half-siblings, or non-cohabiting parents), which coincides with trends discussed in Family Well-being: What makes a difference by McKeown et al (2003, p. 23).

In particular, the urban multi-denominational school had a population drawn from a variety of international backgrounds; a teacher there mentioned the challenge of working where English is the child's second language. The urban private school also had a higherthan-average number of children with a range of international backgrounds, although they did not appear to experience similar difficulties with English as a second language. This difference in experience could perhaps be due in part to more of the children from the multi-denominational school being immigrants themselves and more of the children from the private school being first-generation Irish, or maybe their parents were more established in Ireland.

In most schools, the younger members of the focus group, or the very shy, tended to almost whisper and often had to be asked questions directly — they were less likely to engage freely in discussion. General ground rules, intended to facilitate recording of the sessions, were agreed prior to beginning the focus group work. However, in some schools, the children had more difficulty with the rules. From the researchers' observations, in both Gaelscoileanna, the private school and the multi-denominational school, the children appeared to be highly articulate and were inclined to abide by the ground rules to allow others to take their turn and speak. In one of the designated 'disadvantaged' urban schools, the group appeared to have a little more difficulty with taking turns than the others, and this was the only setting in which the session had to be stopped (twice), resulting in one participant being asked to leave.

The vast majority of the children who participated in this research actively embrace technology and see it as being an intrinsic part of their lifestyle. They aspire to owning an array of entertainment and communications devices, and are confident about their ability to negotiate the technological world. In some groups, children discussed the risks associated with entering chat rooms or revealing personal, identifying information online. Whatever concerns adults may have, children believe that they are able to evaluate situations and content (online or televisual) for themselves. Whether this is true, or if there are potential long-term subliminal effects of exposure to adult-oriented content, has not been established. However, no child volunteered any story of personal distress nor did teachers or parents reveal actual experience of children demonstrating inappropriate behaviours directly related to their TV or games consumption (other than an inability to be attentive in class due to tiredness).

\section{Issues for further research}

Issues for further research emerging from the current study may be summarised as follows: 
- Most children in the current study are growing up in families of two or more children. What role do siblings play in providing play and learning opportunities for children in relation to technology?

- Is there an emerging 'mall culture' among Irish children and to what extent is it centred around children's consumer interests or simply because of the lack of other suitable outdoor venues for socialising?

- What is the extent of the generational gap between children and adults in relation to technology? How adept are children in their use of computers, consoles and other ICT devices? How knowledgeable are their parents about these same platforms and devices?

- Both children and adults strongly value outdoor play activities. But some parents also report great difficulties in encouraging their older children to go out and play. Further research is required on this topic to identify some of the factors governing children's access to and use of outdoor play opportunities.

- Children expressed confidence in their ability to assess and evaluate content on the Internet. How do children go about evaluating online content and what criteria do they apply? What critical media literacy skills do children have in their engagement with media content more generally?

- The rising awareness and use of technology with age is a major finding of this study. At what age and how does this increasing affinity with technology take place? Who are the key influencers - peer groups, parents, siblings, school, other media? How does learning about technology take place?

- The study recorded high levels of ICT possession at home, especially in the households of children attending the designated 'disadvantaged' urban schools. This suggests that the relationship between socio-economic status and the ownership, access and use of technology, is highly complex. This relationship requires further research.

- With the rapid pace of technological change and the imminent deployment of high levels of broadband access, as well as the development of new mobile devices and services, there is an urgent need to research how such technologies will be adopted and used by children. Ideally, the National Longitudinal Study of Children in Ireland, commissioned by the Office of the Minister for Children and commenced in 2006, should incorporate, in some measure, questions on technology access and use. A specific study — as a spur from the main one could be commissioned to study in more depth the technological habits and opportunities available to children and young people.

\section{Policy implications}

In addition to the issues for further research outlined above, there are a number of policy implications of the current research findings, summarised as follows:

- The strong preference for outdoor active play provides major support and endorsement of the strategic objectives of the National Play Policy, in particular Objective 3 ('To ensure that children's play needs are met through the development of a child-friendly environment') and Objective 4 ('To maximise the range of public play opportunities available to children, particularly children who are marginalised or disadvantaged or who have a disability'). Further engagement 
with older children, particularly girls, may be necessary to encourage more active play activities.

- There is relatively little awareness of the statutory and non-statutory regulatory frameworks in Ireland for digital media content, console games, DVDs and videos, and online content. Ratings systems for software are often not heeded. There was no awareness of the Hotline provided by the Internet Service Providers Association of Ireland (available at www.hotline.ie) for the reporting of child pornography. Nor was there any apparent awareness of the Internet Advisory Board (available at www.iab.ie), which provides awareness of online safety.

- With relatively high levels of computer technology in the home, schools by contrast appear to have far fewer resources. While it was not formally studied in this research, schools in many instances appeared to have just one computer in the classroom and of a lower specification than many children would have at home. The deployment of computers in schools has been, and will continue to be, a major focus of public policy and, as such, the adequate resourcing of such programmes is an urgent requirement.

- In addition to adequate levels of computers, whether in the home or at school, there is also a major requirement for carefully designed information packages about information and communication technologies (ICTs) for parents, teachers and others working with children. It was clear from the research that parents in many instances were unaware of, or lacked confidence in, educational applications of computer technology or Internet-based educational content.

- There also needs to be greater emphasis given at policy level to the potential of technology to enrich children's development. It is not just an issue of wider access to technological resources, whether at home or in school. What is important is the context in which technology is understood and the vision for realising its benefits in education, recreation and social life. 


\section{Bibliography}

Attewell, P., Suazo-Garcia, B. and Battle, J. (2003) 'Computers and young children: Social benefit or social problem?’, Social Forces, Vol. 82, No. 1, pp. 277-96.

Belton, T. (2001) 'Television and imagination: An investigation of the medium's influence on children's story-making', Media, Culture and Society, Vol. 23, No. 6, pp. 799-820.

Brennan, M. (2001) 'Free time before tea time': A sociological study of children's free time (unpublished thesis). Dublin: National University of Ireland.

Bruckman, A. (1999) 'Approaches to educational use of the Internet: The Day After Net Day', Convergence, Vol. 5, No. 1, pp. 24-46.

Bruner, J. (1996) The Culture of Education. Cambridge, MA: Harvard University Press.

Bruner, J., Jolly, A. and Sylva, K. (eds.) (1976) Play: Its Role in Development and Evolution. Harmondsworth: Penguin Books.

Buckingham, D. (2000) After the death of childhood: Growing up in the age of electronic media. Oxford: Polity Press.

Buckingham, D. and Scanlon, M. (2001) 'Parental pedagogies: An analysis of British "edutainment" magazines for young children', Journal of Early Childhood Literacy, Vol. 1, No. 3, pp. 281-99.

Buckingham, D. and Scanlon, M. (2002) Education, Entertainment and Learning in the Home. Milton Keynes: Open University Press.

Cawley, A. and Trench, B. (2004) Current Perspectives on the Information Society: Revisiting the Future. Dublin: Information Society Commission.

Christensen, O. and Tufte, B. (2001) Familier i forandring: Hverdag og medier i danske familier ('The changing family: Media in the lives of Danish families'). Copenhagen: Akademisk Forlag.

ComReg (2004) Quarterly Survey, October 2004. Dublin: Commission for Communications Regulation. Available at: www.comreg.ie/publications/docs.asp?s=5\&navid=98\&ydate=2004

CSO (2003) Census 2002. Dublin: Central Statistics Office.

Daly, M. and Leonard, M. (2002) Against all odds: Family life on a low income in Ireland. Dublin: Institute of Public Administration.

Department of Health and Children (2000) The National Children's Strategy: Our Children - Their Lives. Dublin: The Stationery Office.

Devine, D., Nic Ghiolla Phadraig, M. and Deegan, J. (2004) 'Time for Children — Time for Change? Children's rights and welfare in a period of economic growth in Ireland', in Childhood in Ageing Societies: Country Studies on Children's Welfare and Everyday Life, Volume 1, A. Jensen, A. Benn Arieh, C. Conti, D. Kutsar, M. Nic Ghiolla Phadraig and H. Nielsen (eds). Trondheim: Norwegian Centre for Child Research and Tartu University Press.

Dyson, A. (1997) Writing Superheros: Contemporary Childhood, Popular Culture and Classroom Literacy. New York: Teachers' College Press.

Elkind, D. (1988) The Hurried Child: Growing Too Fast Too Soon. Reading, MA: Addison Wesley.

Elkind, D. (1998) Reinventing Childhood: Raising and educating children in a changing world. Rosemont, NJ: Modern Learning Press.

Elkind, D. (2003) 'The Reality of Virtual Stress', CIO Magazine, Fall/Winter.

Fleming, D. (1996) Powerplay: Children, Toys and Popular Culture, Manchester: Manchester University Press.

Fromme, J. (2003) 'Computer games as a part of children's culture', Games Studies: The International Journal of Computer Game Research, Vol. 3, No. 1. Available at: www.gamestudies.org/0301/fromme/

Garvey, C. (1990) Play. London: Fontana.

Gentile, D.A. (ed.) (2003) Media Violence and Children: A Complete Guide for Parents and Professionals. London: Praeger.

Gentile, D.A., Lynch, P.J., Linder, J.R. and Walsh, D.A. (2004) 'The effects of violent video game habits on adolescent hostility, aggressive behaviors and school performance', Journal of Adolescence, Vol. 27, No. 1, pp. 5-22.

Giacquinta, J.B. , Bauer, J.A. and Levin, T. (1994) Beyond Technology's Promise: An examination of children's educational computing at home. Cambridge: Cambridge University Press.

Goldstein, J. (2000) Effects of Electronic Games on Children. Utrecht: University of Utrecht. Available at: www.commerce.senate.gov/hearings/0321gol.pdf

Gunter, B. and McAleer, J. (1997) Children and Television, 2nd Edition. London: Routledge.

Haugland, C. (2000) 'Early childhood classrooms in the 21st century: Using computers to maximise learning', Young Children, Vol. 55, No. 1, pp. 12-18. 
Healy, J. (1998) Failure to connect: How computers affect our children's minds for better or worse. New York: Simon and Schuster.

Hennessy, E. and Heary, C. (2005) 'Exploring Children’s Views through Focus Groups', in Researching children's experience: Approaches and Methods, S. Greene and D. Hogan (eds.). London: Sage Publications.

Himmelweit, H.T., Oppenheim, A.N. and Vince, P. (1958) Television and the Child. Oxford: Oxford University Press.

Hodge, B. and Tripp, D. (1986) Children and Television: A Semiotic Approach. Palo Alto, CA: Stanford University Press.

Hohman, C. (1998) ‘Evaluating and Selecting Software for Children’, Childcare Information Exchange, No. 9, pp. 60-62.

Hoover, S.M., Schofield Clark, L. and Alters, D.F. (2004) Media, Home and Family. London: Routledge.

Amárach Consulting (2004) The Use of New Media by Children. Dublin: Internet Advisory Board. Available at: www.iab.ie/publications/research/d63.pdf

Irish Times (2006) Most schoolchildren own a mobile phone by sixth class - Report on INTO survey, 30 January 2006. Dublin: The Irish Times.

Judge, M. (2003) Wired for learning in Ireland: Final Evaluation Report. Dublin: National Centre for Technology in Education.

Katz, J. (1996) 'The Rights of Kids in the Digital Age’, Wired, Vol. 4, No. 7, pp. 120-23.

Livingstone, S. (2002) Children's Use of the Internet - A Review of the Research Literature. London: National Children's Bureau.

Livingstone, S. (2003) 'Children's use of the Internet: Reflections on the emerging research agenda', New Media and Society, Vol 5, No. 2, pp. 147-66.

Livingstone, S. and Bober, M. (2003) UK Children go online: Listening to young people's experiences. LSE Report. London: London School of Economics and Political Science.

Livingstone, S. and Bovill, M. (1999) Young People and New Media. London: London School of Economics and Political Science.

Livingstone, S. and Bovill, M. (eds.) (2001a) Children and their changing media environment: A European comparative study. London: Lawrence Erlbaum Associates.

Livingstone, S. and Bovill, M. (2001b) Families and the Internet: An observational study of children and young people's Internet use. London: British Telecom. Available at: www.lse.ac.uk/depts/media/people/slivingstone/index.html

Livingstone, S.M. (1990) Making Sense of Television — The Psychology of Audience Interpretation. London: Pergamon Press.

McArdle, J. (2001) ‘Children's Play’, Child: Care. Health and Development, Vol. 27, No. 6, pp. 509-14.

McKeown, K., Pratschke, J. and Haase, T. (2003) Family Well-being: What makes a difference? Shannon: The Céifin Centre and the Department of Social and Family Affairs.

Meyrowitz, J. (1985) No Sense of Place: The impact of electonic media on social behaviour. Oxford: Oxford University Press.

Moyles, J. (1994) The Excellence of Play. Buckingham: Open University Press.

National Health and Lifestyle Surveys (2003) Report of National Health and Lifestyle Surveys, Phase 2. Galway: Centre for Health Promotion Studies, National University of Ireland Galway.

NCO (2004) Ready, Steady, Play! A National Play Policy, National Children’s Office. Dublin: The Stationery Office.

NPADC (2001) The impact of schools IT2000, National Policy Advisory and Development Committee. Dublin: Dublin City University.

Papert, S. (1993) The Children's Machine: Rethinking school in the age of the computer. New York: Basic Books.

Papert, S. (1996) The Connected Family. Atlanta, GA: Longstreet Press.

Papert, S. (2005) 'A conversation with Seymour Papert, Marvin Minsky and Alan Kay', Communications of the ACM, Vol. 48, No. 1, pp. 35-38.

Postman, N. (1994) The Disappearance of Childhood. New York: Vintage Books.

Roberts, D.F. (1999) Kids and Media@the New Millennium: A comprehensive national analysis of children's media use. Menlo Park, CA: Kaiser Family Foundation.

Roberts, D.F. (2000) 'Media and youth: Access, exposure and privatization', Journal of Adolescent Health, Vol. 27, No. 2, pp. 8-14.

Rushkoff, D. (1999) Playing the Future: What we can learn from digital kids. New York: Riverhead Books.

Schramm, W., Lyle, J. and Parker, E. (1961) Television in the lives of our children. Stanford, CA: Stanford University Press. 
Sefton-Green, J. (ed.) (1998) Digital Diversions: Youth culture in the age of multimedia. London: UCL Press.

Seiter, E. (1999) Television and New Media Audiences. Oxford: Oxford University Press.

Sheridan, S. and Pramling-Samuelsson, I. (2003) 'Learning through ICT in Swedish early childhood education from a pedagogical perspective of quality', Childhood Education, Vol. 79, No. 5, pp. 276-77.

Smith, P.K. (1986) Children's play: Research, development and practical application. New York: Gordon \& Breach.

Sorensen Holmes, B. and Jessen, C. (2000) 'Isn't it Real? Children, computer games, violence and reality’, in Children in the New Media Landscape, U. Carlsson and C. von Feilitzen (eds.). Göteborg: UNESCO/Nordicom.

Sutton-Smith, B. (1997) The Ambiguity of Play. Cambridge, MA: Harvard University Press.

Tapscott, D. (1999) Growing Up Digital: The Rise of the Net Generation. New York: McGraw Hill.

Tobin, J. (1998) 'An American otaku (or, a boy's virtual life on the Net)', in Digital Diversions: Youth culture in the age of multimedia, J. Sefton-Green (ed.). London: UCL Press.

Valentine, G., Holloway, S. and Bingham, N. (2002) 'The digital generation? Children, ICT and the everyday nature of social exclusion', Antipode, Vol. 34, No. 2, pp. 296-315.

Valkenburg, P.M. (2004) Children's Responses to the Screen: A media psychological approach. London: Lawrence Erlbaum Associates.

Valkenburg, P.M. and Cantor, J. (2001) 'The development of a child into a consumer', Journal of Applied Developmental Psychology, Vol. 22, No. 1, pp. 61-72.

Wartella, E.A. (2002) 'New Generations - New Media’, Nordicom Review, Vol. 23, No. 1-2, pp. 23-36.

Whyte, J. (1995) Changing Times: A comparative study of children - Belfast, London, Dublin. Aldershot: Avebury.

Winn, M. (1977) Plug in drug: Television, computers and family life. Harmondsworth: Penguin Books.

Winn, M. (1984) Children without Childhood: Growing up too fast in a world of sex and drugs. Harmondsworth: Penguin Books.

Wright, J., Huston, A., Vandewater, E., Bickham, D., Scantlin, R., Kotler, J., Caplovitz, A., Lee, J., Hofferth, S. and Finkelstein, J. (2001) 'American children's use of electronic media in 1997: A national survey’, Journal of Applied Developmental Psychology, Vol. 22, No. 1, pp. 31-47. 


\section{Appendix 1: Play and Technology Questionnaire for younger children (aged 4-8)}

\section{ABOUT ME}

1. Are you:

$\square$ a girl a boy

2. How old are you?

3. Do you have any brothers and sisters? brothers sisters

4. Are they older or younger than you?
the oldest
in the middle
the youngest
only child

\section{WHAT I LIKE TO DO BEST}

5. What is your favourite thing to do when you are playing with your friends?

6. What is your favourite thing to do or play when you are on your own?

THINGS I USE (tick as many of these answers that are true)

7. Do you have any of these things at home? (Circle things in own room)

\begin{tabular}{|l|l|l|l|}
\hline & Books? & $\square$ Yes & No \\
\hline
\end{tabular}




\begin{tabular}{|c|c|c|c|}
\hline & Tape recorder? & $\square$ Yes & $\square$ No \\
\hline & CD player? & $\square$ Yes & $\square$ No \\
\hline & Television? & $\square$ Yes & $\square$ No \\
\hline & Video machine? & $\square$ Yes & $\square$ No \\
\hline & DVD player? & $\square$ Yes & $\square$ No \\
\hline & Computer? & $\square$ Yes & $\square$ No \\
\hline & Does it have Internet access? & $\square$ Yes & $\square$ No \\
\hline & PlayStation or other games machine? & $\square$ Yes & $\square$ No \\
\hline & Gameboy or other pocket game? & $\square$ Yes & $\square$ No \\
\hline & $\begin{array}{l}\text { An electronic musical instrument, } \\
\text { such as keyboard or electric guitar? }\end{array}$ & $\square$ Yes & $\square$ No \\
\hline
\end{tabular}

\begin{tabular}{|c|r|r|r|r|}
\hline \multicolumn{2}{|l|}{ 8a. Do you own a mobile phone? } & \multicolumn{3}{|c|}{ 8b. If yes, is it a camera phone? } \\
\cline { 1 - 3 } & $\square$ Yes & & $\square$ Yes & $\square$ No \\
& & & \\
\hline
\end{tabular}


WHEN I PLAY (tick as many of these answers that are true)

9. Do you play games on computer or PlayStation (or another games machine)?
$\square$ Yes
No

If YES,

9a. Where do you play the games?

$\square \quad$ in my bedroom
$\square \quad$ in a family room at home
$\square \quad$ at a friend's house

9b. Who do you play with or do you play alone?

$\begin{array}{ll}\square & \text { alone } \\ \square & \text { with friends } \\ \square & \text { with my brother or sister } \\ \square \quad \text { with my parents }\end{array}$

10. Do you use the Internet?

$\square$ Yes

No

If YES,

10a. What do you use it for?

\section{WHAT I WOULD LIKE}

11. What do you hope to get for Christmas?

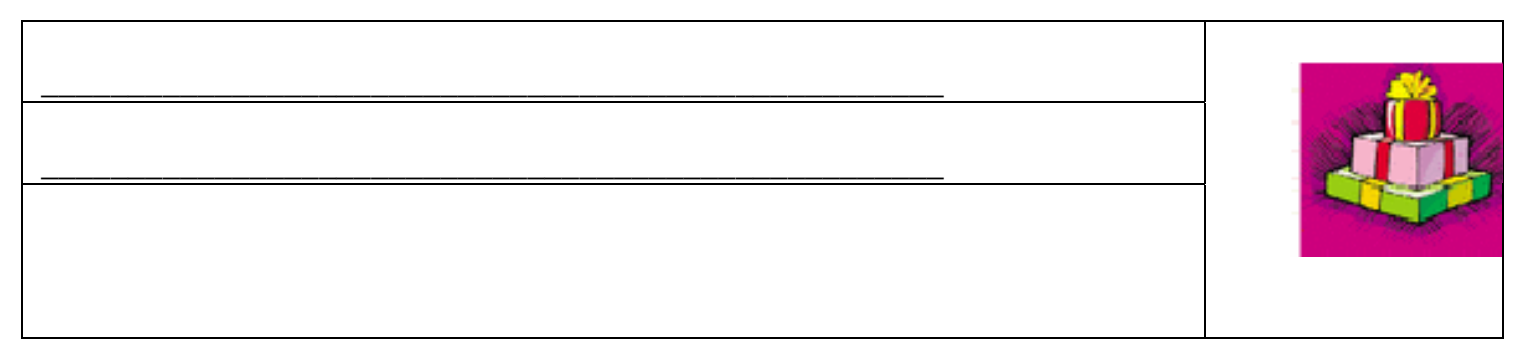

Thank you! 


\section{Appendix 2: Play and Technology Questionnaire for older children (aged 8-12)}

\section{ABOUT ME}

1. Are you:

a girl

a boy

2. How old are you?

3a. How many brothers do you have?

3b. How many sisters do you have?

4. In your family are you

the oldest child $\square \quad$ in the middle $\square \quad$ the youngest child $\square \quad$ only child $\square$

\section{WHAT I LIKE TO DO BEST}

5. What do you like to do with your friends in your free time?

1.

2.

3.

6. What do you like to do on your own in your free time?

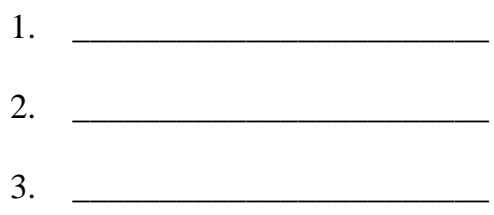

THINGS I USE (tick as many of these answers that are true)

7a. Do you have any of these things at home? Which rooms are they in (e.g. kitchen, living room)?

\begin{tabular}{|l|l|l|l|l|}
\hline & & $\square$ Yes & $\square$ No & \\
\hline
\end{tabular}




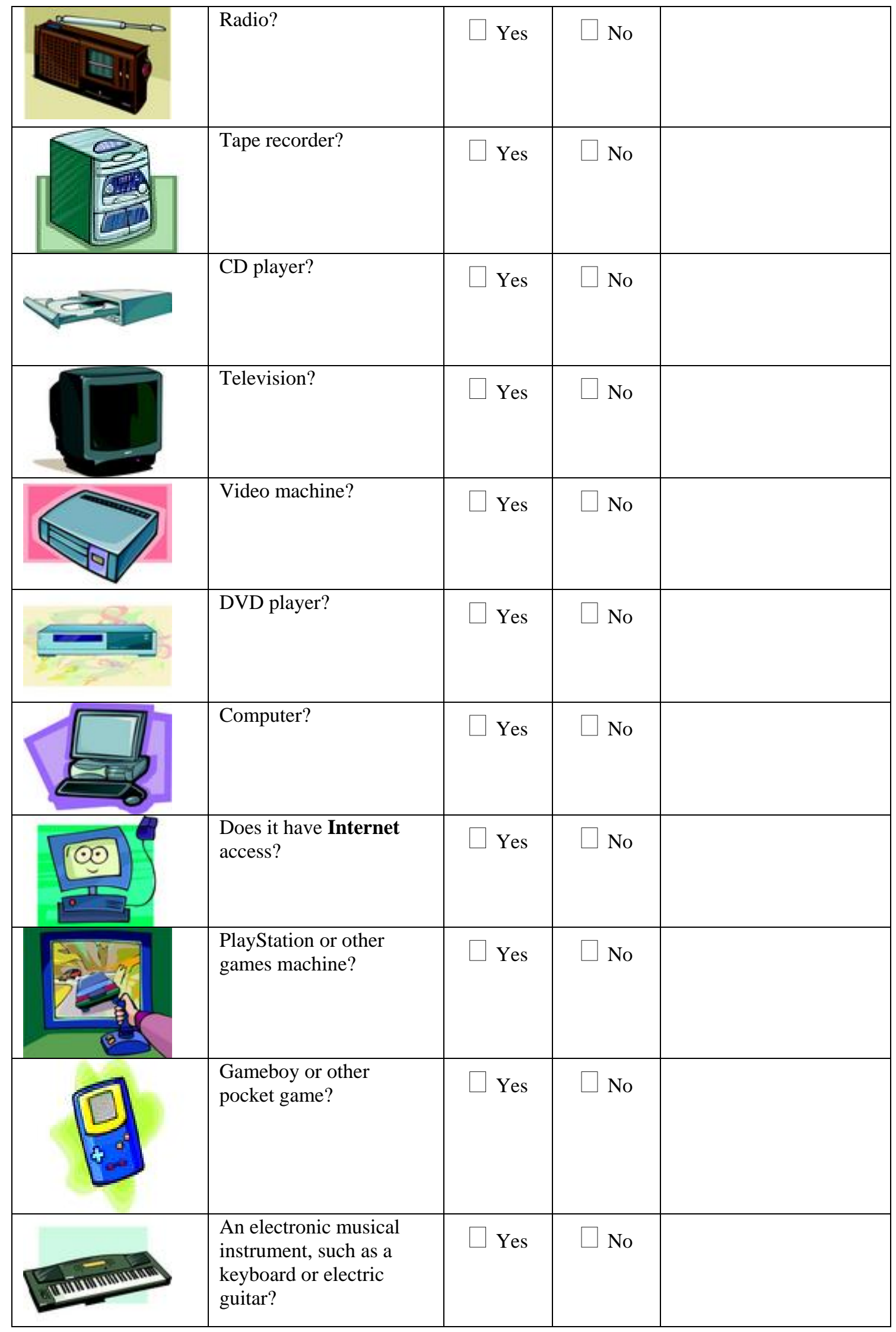

Something else? 
7b. Which, if any, of these do you have in your room?

8a. Do you own a mobile phone?

$\square$ Yes $\square$ No 8b. If yes, is it a camera phone?

Yes $\square$ No

WHEN I PLAY (tick as many of these answers that are true)

9. When I play computer or video games, I play:

in my bedroom

in a family room at home

at a friend's house

10. I like to play computer or video games:

alone

with friends

with my brother or sister

with my parents

11. I use the Internet:

I don't use the Internet

to look up websites to find out about things I am interested in

to play games online

to chat online or send messages

to find game cheats

to listen to music

to watch trailers for films

to do homework or a school project

for something else

\section{WHY I PLAY}

\section{Finish the sentence}

What I like about playing 


\section{WHAT I WOULD LIKE}

13. The three things I would like to get for my next birthday or Christmas are:

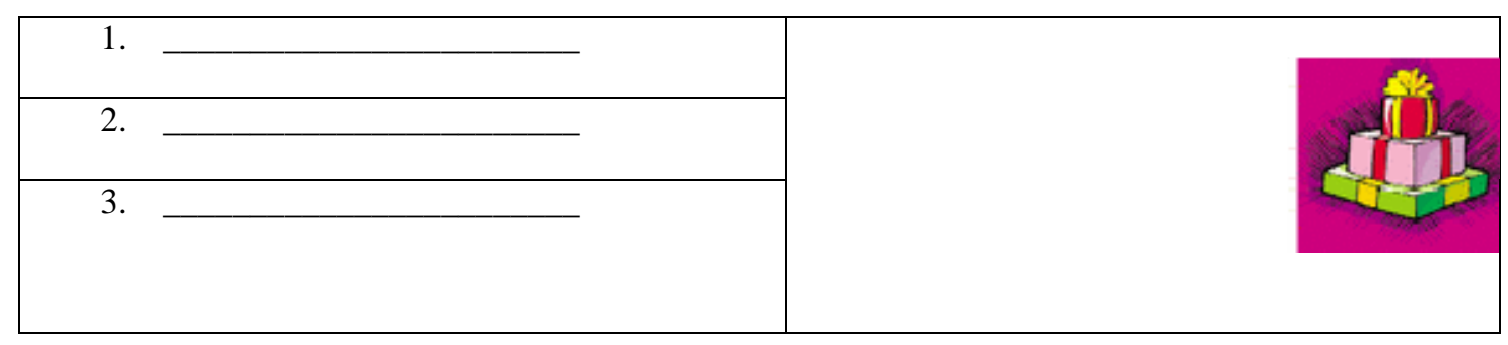

Thank you! 